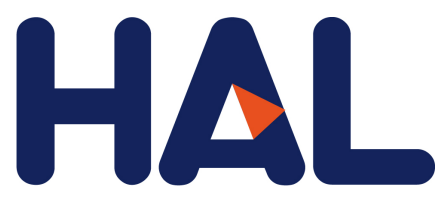

archives-ouvertes

\title{
Silicate melts during Earth's core formation
}

Mohamed Ali Bouhifd, V. Clesi, A. Boujibar, N. Bolfan-Casanova, C. Cartier, Tahar Hammouda, M. Boyet, Geeth Manthilake, J. Monteux, Denis Andrault

\section{To cite this version:}

Mohamed Ali Bouhifd, V. Clesi, A. Boujibar, N. Bolfan-Casanova, C. Cartier, et al.. Silicate melts during Earth's core formation. Chemical Geology, Elsevier, 2017, 461, pp.128 - 139. 10.1016/j.chemgeo.2016.12.035 . hal-01635980

\section{HAL Id: hal-01635980 https://hal.uca.fr/hal-01635980}

Submitted on 9 Dec 2019

HAL is a multi-disciplinary open access archive for the deposit and dissemination of scientific research documents, whether they are published or not. The documents may come from teaching and research institutions in France or abroad, or from public or private research centers.
L'archive ouverte pluridisciplinaire HAL, est destinée au dépôt et à la diffusion de documents scientifiques de niveau recherche, publiés ou non, émanant des établissements d'enseignement et de recherche français ou étrangers, des laboratoires publics ou privés. 


\title{
Silicate melts during Earth's core formation
}

\author{
M.A. Bouhifd a,*, V. Clesi a , A. Boujibar ${ }^{\text {b }}$, N. Bolfan-Casanova ${ }^{\text {a }}$, C. Cartier ${ }^{\mathrm{c}}$, T. Hammouda $^{\text {a }}$, M. Boyet ${ }^{\text {a }}$, \\ G. Manthilake ${ }^{a}$, J. Monteux ${ }^{a}$, D. Andrault ${ }^{\mathrm{a}}$ \\ a Laboratoire Magmas et Volcans, Université Blaise Pascal, CNRS UMR 6524, Campus Universitaire des Cézeaux, 6 Avenue Blaise Pascal, 63178 Aubière Cedex, France \\ ${ }^{\mathrm{b}}$ NASA Johnson Space Center, 2101 Nasa Parkway, Houston, TX 77058, USA \\ c Department of Geology (B20), Université de Liège, B-4000 Sart Tilman, Belgium
}

\section{A R T I C L E I N F O}

\section{Article history:}

Received 3 March 2016

Received in revised form 17 December 2016

Accepted 21 December 2016

Available online $\mathrm{xxxx}$

\section{Keywords:}

Magma ocean

Earth's core

Magma ocean crystallization

Bridgmanite

Liquidus

Helium

Nb-Ta paradox

Redox state

\begin{abstract}
A B S T R A C T
Accretion from primordial material and its subsequent differentiation into a planet with core and mantle are fundamental problems in terrestrial and solar system. Many of the questions about the processes, although well developed as model scenarios over the last few decades, are still open and much debated. In the early Earth, during its formation and differentiation into rocky mantle and iron-rich core, it is likely that silicate melts played an important part in shaping the Earth's main reservoirs as we know them today.

Here, we review several recent results in a deep magma ocean scenario that give tight constraints on the early evolution of our planet. These results include the behaviour of some siderophile elements ( $\mathrm{Ni}$ and $\mathrm{Fe}$ ), lithophile elements ( $\mathrm{Nb}$ and $\mathrm{Ta}$ ) and one volatile element (Helium) during Earth's core formation. We will also discuss the melting and crystallization of an early magma ocean, and the implications on the general feature of core-mantle separation and the depth of the magma ocean. The incorporation of $\mathrm{Fe}^{2+}$ and $\mathrm{Fe}^{3+}$ in bridgmanite during magma ocean crystallization is also discussed. All the examples presented here highlight the importance of the prevailing conditions during the earliest time of Earth's history in determining the composition and dynamic history of our planet.
\end{abstract}

\section{Introduction}

Silicate melts have played an important role in Earth's evolution from the core formation 4.5 billion years ago to present-day volcanic activity. Modern planetary formation models show that terrestrial planets likely formed through three modes of growth that were ordered in time in the protoplanetary disk. In step I, km-sized planetesimals formed by the coagulation of gas and dust in less than $\sim 10^{4}$ years. In step II, the collisional evolution of the planetesimals population led to the growth of Moon to Mars-sized planetary embryos formed by runaway growth through collisions among the planetesimals in $<10^{6}$ years. In step III, giant collisions among the planetary embryos resulted in the formation of a few terrestrial planets that swept up all the other bodies. This stage may have taken up to $\sim 10^{8}$ years (e.g. Chambers, 2004; Morbidelli et al., 2012). At least step II and step III were energetic enough to have likely melted a large fraction of the silicate Earth (e.g. Canup, 2012). Theory and observations point in fact to the occurrence of magma oceans in the early evolution of terrestrial planets and in many planetesimals (e.g. Greenwood et al., 2005; Elkins-Tanton, 2012). In addition a magma ocean scenario provides a favorable environment in which metal-silicate segregation can occur rapidly and efficiently (e.g. Stevenson, 1990).

\footnotetext{
* Corresponding author.

E-mail address: A.Bouhifd@opgc.univ-bpclermont.fr (M.A. Bouhifd).
}

It is now well established that for metal and silicate to segregate rapidly on a planetary scale requires that at least the metal is molten (Stevenson, 1990). On the other hand, when the silicate is also largely molten, liquid metal can segregate extremely efficiently (e.g. Rubie et al., 2003). The short time scale of Earth's core formation, ranging from 30 to $100 \mathrm{Ma}$ after the beginning of solar system accretion (e.g. Kleine et al., 2009) can be also used as an indirect evidence for large scale melting during the first $100 \mathrm{Ma}$ of Earth's history. There are three main sources of energy that can produce the melting that is required for core formation: (1) the decay of short-lived radioactive nuclides $\left({ }^{26} \mathrm{Al}\right.$ and ${ }^{60} \mathrm{Fe}$ ) during the first 1-3 $\mathrm{Ma}$ of the solar system evolution (Yoshino et al., 2003); (2) the energy delivered by impacts that can generate local or global melting especially during the late stages of Earth accretion (Tonks and Melosh, 1993); (3) the conversion of potential energy into heat via viscous dissipation during the segregation of the metallic phase that can increase the silicate temperature by 1000 $3000^{\circ}$ (Ke and Solomatov, 2009; Monteux et al., 2009; Samuel et al., 2010; more details can be found in the review paper by Rubie et al., 2015b).

Melting events are common in the first stages of Solar System history and start very rapidly after the beginning of solar nebula condensation, dated at 4.567-4.568 Ga, age of refractory inclusions, known as CAIs (see Amelin et al., 2002; Bouvier and Wadhwa, 2010; Connelly et al., 2012). Oldest ages measured in iron meteorites show that metal-silicate separation began on planetesimals within 1 to $1.5 \mathrm{Ma}$ of the start of 
Solar System formation (Kruijer et al., 2012, 2014). The study of basaltic achondrites (angrites, eucrites) coming from different parent bodies shows that small planetesimals have experienced magma ocean stages during the first million years of their history (e.g. Brennecka and Wadhwa, 2012; Touboul et al., 2015). This chronology shows that the building blocks of forming planets implied mainly differentiated objects instead of primitive and undifferentiated materials. In planets, the last stages of accretion end with very large collisions. The most spectacular event for Earth corresponds to the Moon-forming giant impact event. The study of short-lived systematics in terrestrial samples gives evidence for successive magma-ocean stages on Earth. Noble gas systematics trace the mantle's degassing and the Xenon isotope signature is consistent with extensive loss of volatile elements within the first $100 \mathrm{Ma}$ of Earth's existence (Allègre et al., 1983; Yokochi and Marty, 2005; Mukhopadhayay, 2012). The high ${ }^{3} \mathrm{He} /{ }^{22} \mathrm{Ne}$ fractionation observed in the Earth's mantle suggests at least two separate magma ocean steps during the Earth's accretion (Tucker and Mukhopadhyay, 2014). Excesses in ${ }^{182} \mathrm{~W}$ (produced by the decay of ${ }^{182} \mathrm{Hf}$ ) measured in $2.7 \mathrm{Ga}$-old komatiites are explained by a large-scale magmatic differentiation during the first $30 \mathrm{Ma}$ of the Solar System's history (Touboul et al., 2012). Since the giant Moon-forming impact is dated between 40 and $200 \mathrm{Ma}$ (Boyet et al., 2015 and references therein), this collision may not have induced a complete homogenization of the Earth's mantle. The combined measurements of ${ }^{146,147} \mathrm{Sm}^{-142,143} \mathrm{Nd}$ systematics of undisturbed Eoarchean metabasalts (from the southwestern part of Greenland, Isua Supracrustal Belt) suggest differentiation of the mantle source at $\sim 4.47 \mathrm{Ga}$ (Rizo et al., 2011). Chemical fractionation would have occurred during the crystallization of a large magma ocean which extended down into the lower mantle. This chronology is consistent with the presence of zircon formed in a terrestrial crust at $\sim 4.4 \mathrm{Ga}$ (Wilde et al., 2001; Valley et al., 2014).

Concerning the Earth one of the most important events during the first $100 \mathrm{Ma}$ is the segregation of the metallic core. Among the several uncertainties about the formation of the Earth and other planets, the physical conditions upon which Earth differentiated are important questions that remain much debated. Evidence on the earliest times on Earth comes mainly from two sources: (1) The concentrations of core-forming elements left behind in the silicate part provide a fingerprint on the conditions under which this segregation occurs. (2) The Moon is the second important source of evidence, it is believed to have formed after the Earth's core formation as a result of a giant impact between Earth and a Mars-size body (named Theia) (Hartmann and Davis, 1975; Tonks and Melosh, 1993). The magma oceans were reservoirs where partial to complete equilibrium and segregation of the metallic phase from the impactor and the silicate phase from the target were likely to occur (Rubie et al., 2003). The thermo-chemical exchanges that occurred in the magma oceans have strongly influenced the geochemical signature within the current deepest parts of the Earth. Hence they play a key role on how we constrain the differentiation processes in terms of characteristic timescales, $\mathrm{P}$ - T conditions or redox conditions. The metal silicate separation processes and especially the characteristic volumes that are involved (cm-droplets to km-diapirs) during the core formation govern the degree of chemical equilibration between the mantle and the core of the Earth (Samuel, 2012; Wacheul et al., 2014). During the latest stages of planetary accretions the large impactors were probably differentiated. After a collision, the impactor's core is assimilated into the partially to completely molten mantle leading to a first fragmentation due to the impact itself. This first fragmentation is poorly constrained but it is the starting point of the second fragmentation that is likely to occur within the turbulent magma ocean. During these two stages of fragmentation, the impactor's core was potentially fragmented down to $\mathrm{cm}$-size droplets (Rubie et al., 2003). If the impactor's core was completely emulsified in droplets ("iron rain scenario"), the thermo-chemical exchanges between the metallic phase from the impactor and the silicates from the magma ocean were extremely efficient (Rubie et al., 2003). Many geochemical models are based on this "iron rain scenario". However, after a large impact, the emulsification of the impactor's core might be incomplete and large volumes of iron may sink without experiencing a complete equilibration with the mantle they are passing through (Dahl and Stevenson, 2010). In this case, a limited fraction of the mantle could equilibrate with the metallic phase. This could explain the relatively high abundance of highly siderophile elements of the terrestrial mantle that should have efficiently segregated into the core. Recently, laboratory experiments have constrained the mixing (Deguen et al., 2011, 2014) and the fragmentation dynamics (Wacheul et al., 2014) during the sinking of a metallic volume within a magma ocean. Wacheul et al. (2014) showed that there was a wide range of metallic droplet sizes and shapes as well as important interactions within the sinking metal cloud in which fragmentation and coalescence events are superimposed. For the first time, Wacheul et al. (2014) have estimated the influence of the viscosity contrast between liquid iron and the liquid silicates and showed that a large viscosity contrast favors large-scale diapirs. The characteristic size (that governs the sinking velocity) and the shape of the metallic droplets (that governs the exchange surface) are both key parameters to anticipate the degree of equilibration of any chemical element within a magma ocean (Rubie et al., 2003). This degree of equilibration is a strong function of the partition coefficient of each element considered (Deguen et al., 2014).

In summary, the Earth accreted over a period of at least $100 \mathrm{Ma}$ with several magma ocean episodes. During this period the main part of core formation process occurred. In this paper we will review results involving exchanges between molten silicate and metal liquid during the first $100 \mathrm{Ma}$ that give rise to strong constraints on the evolution of our planet. This review includes the conditions of the Earth's core formation determined from the behaviour of some siderophile elements ( $\mathrm{Ni}$ and $\mathrm{Fe}$ ) and lithophile elements ( $\mathrm{Nb}$ and $\mathrm{Ta}$ ). Recent results also show that the early core could have incorporated enough helium to supply deep-rooted plumes with high ${ }^{3} \mathrm{He} /{ }^{4} \mathrm{He}$ ratios throughout the age of the Earth. We will discuss the melting and crystallization of an early magma ocean, and the implications on the general feature of core-mantle separation and the depth of the magma ocean. We will also discuss the incorporation of $\mathrm{Fe}^{2+}$ and $\mathrm{Fe}^{3+}$ in bridgmanite during magma ocean crystallization.

\section{Conditions during Earth's core formation}

\subsection{Constraints from siderophile elements}

The knowledge of the pressure, temperature and oxygen fugacity $\left(f_{\mathrm{O} 2}\right)$ conditions prevailing during Earth's core formation is derived mainly from the behaviour of the siderophile elements (iron loving elements) that are depleted in the mantle. In this context, the behaviour of $\mathrm{Ni}$ and $\mathrm{Co}$ has been considered to provide an important clue, both being refractory elements and present in the Earth's mantle in a near-chondritic Ni to Co ratio (Newsom, 1990). In addition, Ni and Co are almost identical to Fe in cosmochemical volatility (Grossman, 1972; O'Neill and Palme, 1998). By using all existing data of metal - silicate partitioning of $\mathrm{Ni}$ and $\mathrm{Co}$ the consensus at the present time is that metal-silicate equilibration at high pressures, in the range of 40$60 \mathrm{GPa}$ (corresponding to depths of $1000-1500 \mathrm{~km}$ ), was required to produce the observed $\mathrm{Ni}$ and Co depletions in the mantle (see: Bouhifd and Jephcoat, 2011; Righter, 2011; Fischer et al., 2015; Siebert et al., 2012; for the most recent studies). Similar conclusions were reached based on the metal-silicate partitioning of lithophile and weakly-siderophile elements (Mann et al., 2009; Siebert et al., 2011). One should note here that the conditions of Earth's core formation derived from metal-silicate partitioning of siderophile elements cannot be used as arguments for single-stage core formation as this is highly unlikely considering that Earth's core formation occurred during a series of large impact events (e.g. Canup, 2008; O'Brien et al., 2006; Morbidelli et al., 2012; Wetherill, 1985). Such impacts added Fe-rich 
metal which segregated to the Earth's proto-core. The experimental results of metal - silicate partitioning of $\mathrm{Ni}$ and Co suggest only that some impactor must re-equilibrate in the deep magma ocean above $40 \mathrm{GPa}$, presumably as a result of emulsification (Rubie et al., 2003) before reaching the center of our planet to form the core, and leaving the observed mantle abundances of siderophile elements.

\subsubsection{Silicate melts structure control on metal-silicate partitioning of $\mathrm{Ni}$}

As noted above, $\mathrm{Ni}$ is the most studied element to constraint the conditions of Earth's core formation. The available experimental data of molten metal - silicate liquid partitioning of Ni that range from about 1 GPa up to 100 GPa (e.g. Li and Agee, 1996, 2001; Thibault and Walter, 1995; Ohtani and Yurimoto, 1996; O'Neill et al., 1998; Gessmann and Rubie, 2000; Bouhifd and Jephcoat, 2003, 2011; Chabot et al., 2005; Siebert et al., 2012; Fischer et al., 2015; and references therein) show a decrease of metal-silicate partition coefficients of $\mathrm{Ni}$ $\left(D_{\mathrm{Ni}}\right)$ with increasing pressure (at roughly constant oxygen fugacity and temperature following the liquidus of chondritic mantle). Another important feature of $D_{\mathrm{Ni}}$ versus pressure is its marked slope change for pressures higher than 35 GPa. As noted by Sanloup et al. (2013), this slope change coincides with a change in the coordination of silicon (in a basaltic melt composition) from 4 -fold coordination under ambient conditions to 6 -fold coordination at about $35 \mathrm{GPa}$. One can note that similar results were obtained by studying the structure of basaltic melt at high pressures using first-principles simulations (Bajgain et al., 2015). The similarity of the transition pressure from 4- to 6-fold coordination of $\mathrm{Si}$ and the pressure of the marked change in the $D_{\mathrm{Ni}}$ coefficients indicates that melt compressibility controls siderophile-element partitioning - at least for Ni (Sanloup et al., 2013). For other siderophile elements, like $\mathrm{Cr}, \mathrm{V}$ or $\mathrm{Mn}$, metal-silicate partition coefficients versus pressure do not show any slope change at around $35 \mathrm{GPa}$ (see Fischer et al., 2015 for experiments up to $100 \mathrm{GPa}$ ). We reported in Fig. 1 a compilation of $D_{\mathrm{Fe}}$ versus pressure up to about $55 \mathrm{GPa}$ that shows no slope change at around $35 \mathrm{GPa}$ (the reported experiments in Fig. 1 are at $f_{\mathrm{O} 2}$ varying between IW-1 and IW-2). These examples show that melt compressibility is not affecting all siderophile elements partitioning in the same way.

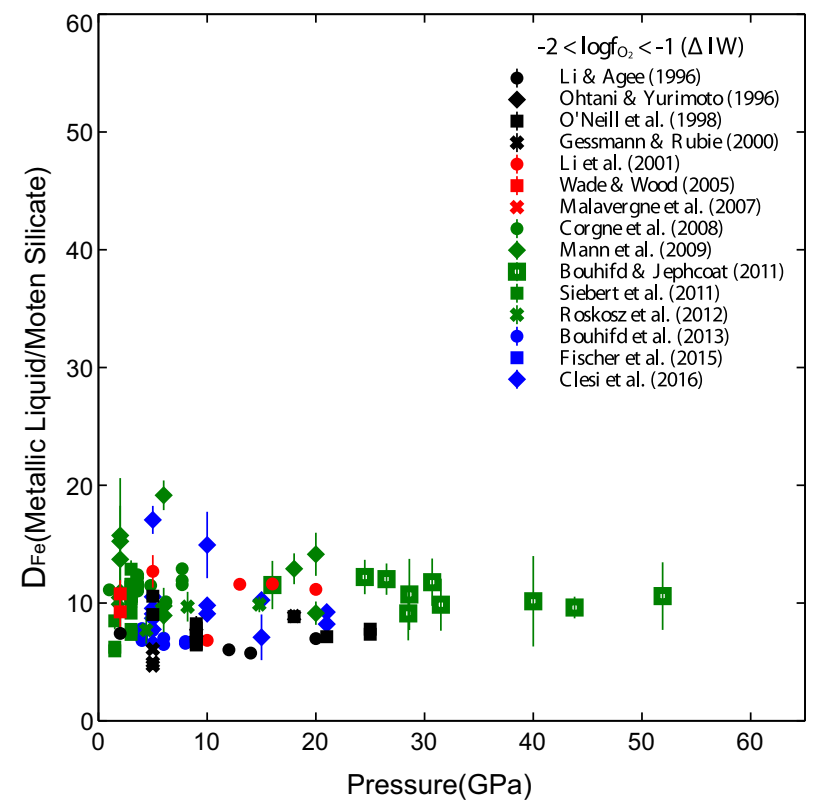

Fig. 1. Molten metal - silicate liquid partition coefficients of $\mathrm{Fe}$ as a function of pressure (GPa). The temperatures of the experiments were above the liquidus of a chondritic composition, and the oxygen fugacity ranges between IW-2 and IW- 1 . The compiled data are taken from the authors reported in the figure.

\subsection{Constraints from refractory lithophile elements}

How elements are distributed between the main reservoirs (core, magma ocean, atmosphere) during planetary differentiation depends on their chemical affinity. Geochemists and cosmochemists have divided the chemical elements into groups, such as the iron-loving siderophile elements, the silicate-loving lithophile elements, the gas phase-loving atmophile elements, and the sulfur-loving chalcophile elements (Goldschmidt, 1937). This classification has been constructed based on the form in which the elements are encountered at the Earth's surface, i.e. under ambient pressure and temperature, and oxidizing conditions. However, each element behaviour is likely to be modified by intensive parameters variations. This is illustrated in the following for the case of $\mathrm{Nb}$ and Ta distribution between molten metal and silicate, this pair of elements giving important clues on oxygen fugacity prevailing during early Earth history.

\subsubsection{Oxygen fugacity effect on metal - Silicate partitioning of $\mathrm{Nb}$ and $\mathrm{Ta}$}

The variation of the partitioning with the oxygen fugacity $\left(f_{\mathrm{O} 2}\right)$ of any cation in silicate liquid informs on its electronic charge in the silicate melt. In fact, metal-silicate partitioning of an element $\mathrm{M}$ between silicate and metal involves exchange between oxidized species $\left(\mathrm{MO}_{\mathrm{n} / 2}\right)$ in the silicate and reduced species in the metal $(\mathrm{M})$. This exchange reaction must depend on oxygen fugacity and the oxidation state $n$ of the element $\mathrm{M}$ in the silicate melt as reported in the following equation:

$\mathrm{MO}_{\mathrm{n} / 2}=\mathrm{M}+\mathrm{n} / 4 \mathrm{O}_{2}$

Working with trace elements, some simplifying assumptions can be made to express their activities and the equilibrium constant can be approximated to the Nernst partition coefficient, yielding the following equation:

$D_{M}=\frac{X_{M}^{\text {alloy }}}{X_{M}^{\text {silicate }}} \approx \frac{a_{M}^{\text {alloy }}}{a_{M}^{\text {silicate }}}=\exp \left(-\frac{\Delta G^{0}}{R T}\right)-\frac{n}{4}\left(f O_{2}\right)$

with $\mathrm{X}$ representing the weight fractions, $a$ the activities, $\Delta G^{0}$ the Gibbs free energy change at the standard state and $\mathrm{fO}_{2}$ the oxygen fugacity. According to the Eq. (3) the metal-silicate partition coefficient for any cation is inversely related to the oxygen fugacity. Additionally, it is also a function of the element valence state in the silicate melt. It can also be predicted that, in theory, any element should become siderophile, provided that the conditions are sufficiently reducing. The most reducing conditions recorded in the solar system are those of calcium aluminium refractory inclusions (CAIs) of carbonaceous chondrites, about 7 log units below Fe-FeO equilibrium (IW-7) (Grossman et al., 2008). (Note that enstatite chondrite conditions may have been even lower, of the order of IW-10 (Larimer and Buseck, 1974).

\subsubsection{The "Nb paradox"}

As the Earth accreted and differentiated, metallic materials segregated from silicates to form the iron-rich core. Because they were excluded from the core, the proportions of the refractory lithophile elements left over in the silicate part of the Earth are thought to have remained identical to those of chondritic meteorites throughout accretion (Kargel and Lewis, 1993). Niobium and tantalum, two refractory elements, have been classified as high field strength elements (HFSE), because their ionic charge over ionic radius ratio is high. This electronic feature mostly defines $\mathrm{Nb}$ and Ta behaviour in magmatic systems: as their sizes differ significantly from that of the available lattices in most of the common minerals, both elements tend to partition into the liquid phase during melting (Hofmann, 1988). Moreover Nb and Ta are described as "geochemical twins": they are known to occur only in pentavalent state and octahedrally coordinated (VI-fold) in geological systems, and share the same ionic radius (0.64 ̊, Shannon, 1976). For those reasons, 
$\mathrm{Nb}$ and Ta should behave similarly during the extraction of the core. However, the $\mathrm{Nb} / \mathrm{Ta}$ ratio of the bulk silicate Earth (BSE) is significantly lower $\left(\mathrm{Nb} / \mathrm{Ta}_{(\mathrm{BSE})}=14 \pm 0.3\right)$ than the chondritic value $(\mathrm{Nb} /$ $\left.\mathrm{Ta}_{\text {(chondrites) }}=19.9 \pm 0.6\right)$, as well as lunar rocks $\left(\mathrm{Nb} / \mathrm{Ta}_{(\text {Moon })}=\right.$ $17.0 \pm 0.8$ (Münker et al., 2003)). This observation is quoted as the "niobium paradox". To resolve this paradox, three main explanations have been proposed: the Earth has a hidden silicate reservoir characterized by a superchondritic $\mathrm{Nb} / \mathrm{Ta}$ that originated from the subduction of refractory eclogite through Earth's history (Rudnick et al., 2000); early storage of the late stage residual melt from the magma ocean (Nebel et al., 2010); the 'missing $\mathrm{Nb}^{\prime}$ " has been sequestrated into the core (Cartier et al., 2014; Wade and Wood, 2001).

\subsection{3. $\mathrm{Nb}$ and Ta partitioning between metal and silicate melts}

Various experimental studies support the idea that the core may be the "missing Nb" reservoir. The results are based on Nb and Ta metal-silicate melts partition coefficients, which appear to be mainly dependent on oxygen fugacity, compared to pressure, temperature or silicate composition (Cartier et al., 2014). When plotted as a function of oxygen fugacity (Fig. 2), partition coefficients describe lines which slopes that depend directly on the cation valence state in the silicate melt.

Under moderately reducing conditions (IW to IW-3) data are consistent with $\mathrm{Nb}_{2} \mathrm{O}_{5}$ and $\mathrm{Ta}_{2} \mathrm{O}_{5}$ in the silicate melt, i.e. $\mathrm{Nb}$ and Ta are mainly $5+$ in the silicate liquid. More surprisingly, $\mathrm{Nb}$ and Ta describe different slopes under very reducing conditions (for $f_{\mathrm{O} 2}>\mathrm{IW}-3$ ), consistent with $\mathrm{NbO}$ and $\mathrm{Ta}_{2} \mathrm{O}_{3}$ in the silicate melts. This contrasting valence change of $\mathrm{Nb}$ and Ta under reducing conditions is responsible for the two elements decoupling in metal - silicate systems. One can note here that the observed behaviour above for $\mathrm{Nb}$ and $\mathrm{Ta}$ is not a general feature for all lithophile elements as for Sm and Nd for example we did not observe any slope break of $D_{\mathrm{Sm}}$ and $D_{\mathrm{Nd}}$ as a function of oxygen fugacity in the range of IW-5 and IW-1. The reported results for Sm and Nd for Sfree systems are consistent with Sm and Nd being dissolved in the silicate melt as $\mathrm{Sm}^{3+}$ and $\mathrm{Nd}^{3+}$ in reducing conditions between IW-5 and IW-1 (Bouhifd et al., 2015). Thus, partitioning data is a good tool to reveal element valence states. However the uncertainty on the element valence state is quite large, because of experimental and analytical error, coupled with significant uncertainties on experimental samples intrinsic oxygen fugacity estimation. The slope is also a function of the interaction coefficient of the element which can vary as Si enters the metal at low $f_{\mathrm{O} 2}$ - this is another good reason to independently constrain the valence through spectroscopy with direct valence probing in the samples.

\subsection{4. $\mathrm{Nb}$ and Ta speciation in silicate melts}

In a recent study, XANES spectra have been acquired in silicate glasses equilibrated under moderately and highly reducing conditions (Fig. 2) (Cartier et al., 2015). Under moderately reducing conditions, the studied silicate glasses mainly contain $\mathrm{Nb}$ and $\mathrm{Ta}$ in the $5+$ state. Under highly reducing conditions, silicate glasses contain $\mathrm{Nb}^{2+}$ and $\mathrm{Ta}^{3+}$. These results confirm the information about $\mathrm{Nb}$ and Ta valence obtained with partition coefficients. Thus $\mathrm{Nb}$ and $\mathrm{Ta}$ behaviour in metal - silicate melts systems is mainly controlled by redox conditions, which simplifies the modeling of their partition coefficients as a function of oxygen fugacity.

\subsection{5. $\mathrm{Nb} /$ Ta ratio as an $\mathrm{fO}_{2}$ proxy during core formation}

The results presented here show that $\mathrm{Nb} / \mathrm{Ta}$ ratio in the primitive magma ocean depends mainly on the prevailing oxygen fugacity. Additionally, the experiments show that pressure has no effect (Cartier et al., 2014), meaning that Nb-Ta systematics cannot be used to estimate the depth of the magma ocean, in contrast to $\mathrm{Ni}$ and $\mathrm{Co}$ for example. NbTa systematics, however, can be used to shed light on the oxidation state of the planet primitive building blocks.

For this, planet growth from planetesimals has been modeled in light of $\mathrm{Nb} / \mathrm{Ta}$ evolution in the magma ocean during core formation. As noted above, when observed, Nb depletion is likely due to its trapping in the metallic core. Therefore, present day Earth's mantle bears the evidence of a reduced stage at some early stage of our planet history. By applying the metal-silicate partitioning data to a heterogeneous accretion scenario (such as proposed by Rubie et al., 2011) it is possible to reach the observed subchondritic $\mathrm{Nb} / \mathrm{Ta}$ ratio $(14 \pm 0.3)$ of the bulk silicate Earth (Fig. 3). According to this scenario, the first $70 \mathrm{wt} \%$ of the Earth accreted from reduced material, similar to enstatite chondrites, except for its lower volatile content, yielding extremely low $\mathrm{Nb} / \mathrm{Ta}$ in the silicate mantle. The last $30 \%$ consist of more oxidized material, allowing for $\mathrm{Nb} / \mathrm{Ta}$ to increase, until it reaches its present day value.

In the case of the Moon, the $\mathrm{Nb} / \mathrm{Ta}$ estimate is of $17.0 \pm 0.8$ (Münker et al., 2003). It is higher than the Earth's value, but still subchondritic. Noting that the Moon's core is very small and has a negligible effect on $\mathrm{Nb}$ budget, the $\mathrm{Nb} / \mathrm{Ta}$ of the Moon mantle is necessarily the result of the mixing of the proto-Earth mantle with the impactor Theia. Considering that terrestrial and lunar samples are isotopically similar, a successful scenario is that at the time of impact, the Moon may have inherited the chemical signature of the Earth's upper mantle, whose $\mathrm{Nb} / \mathrm{Ta}$ was higher than the modern value due to the crystallization of bridgmanite. This signature would have been subsequently erased due to the homogenization of the whole Earth's mantle. $\mathrm{Nb} / \mathrm{Ta}$ ratio is
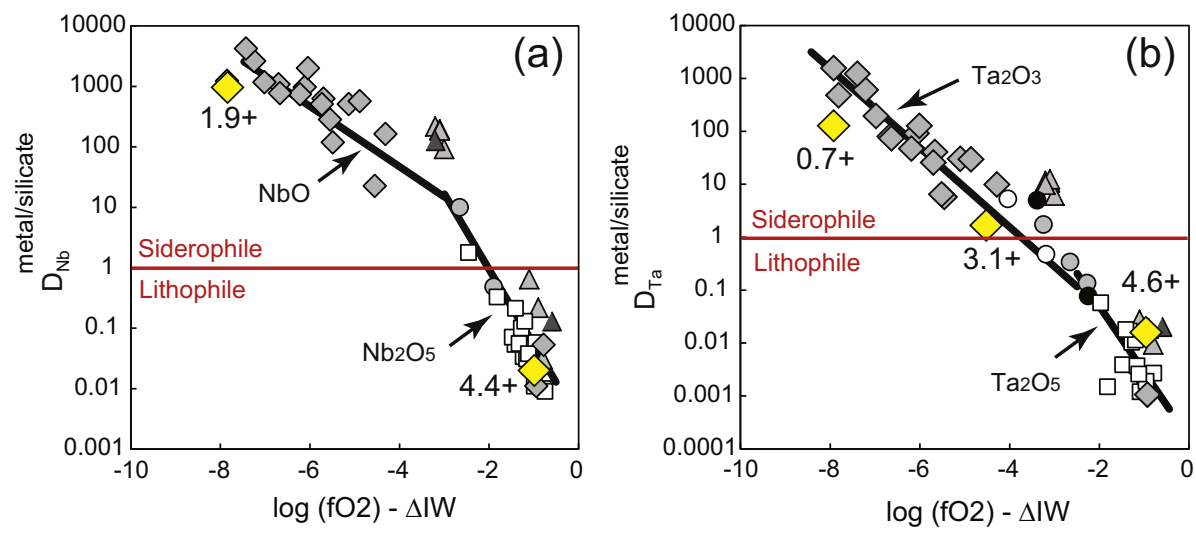

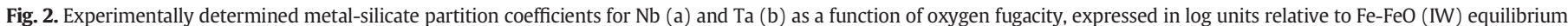

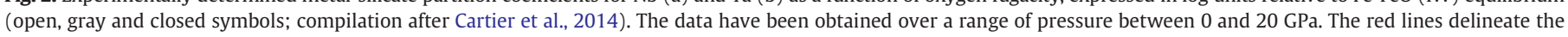

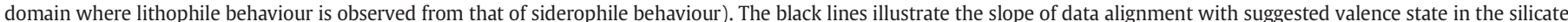

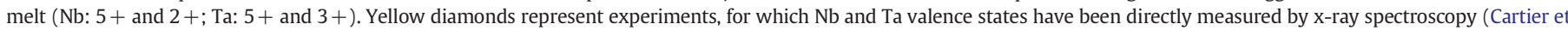

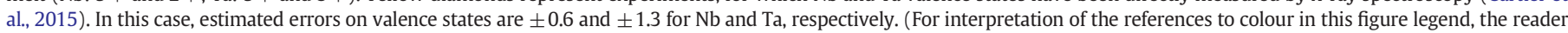
is referred to the web version of this article.) 


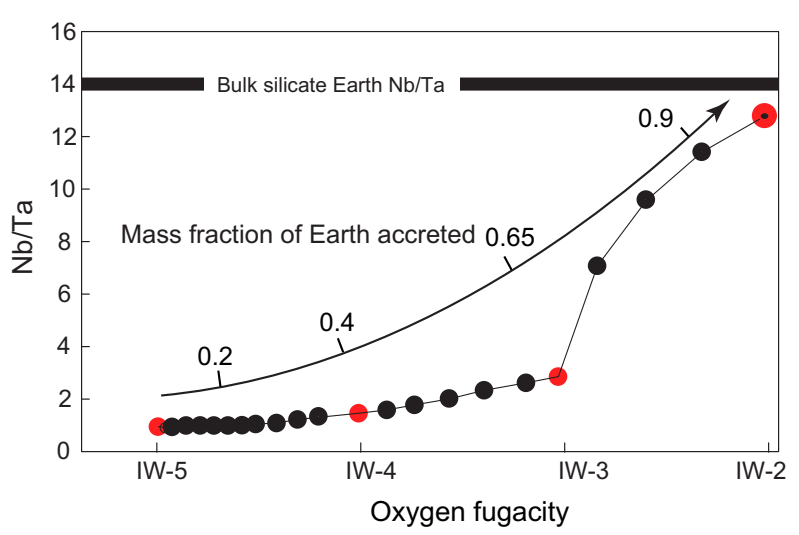

Fig. 3. Evolution of the Earth's mantle $\mathrm{Nb} / \mathrm{Ta}$ ratio during the planet growth as a function of oxygen fugacity (after Cartier et al., 2014). The model considers the accumulation of impactors, starting with reduced and small-sized bodies, followed by less reduced and larger objects (Rubie et al., 2011). This accretion model also considers the degree of mixing (core - mantle equilibration) after each impact. The first stages are characterized by very low $\mathrm{Nb} / \mathrm{Ta}$ ratios, due to massive core uptake. The last bodies accreted are more oxidized and their metallic parts do not fully equilibrate with the mantle, yielding to an increase of the $\mathrm{Nb} / \mathrm{Ta}$ ratio, up to the current estimated value of 14 . The arrow indicates the corresponding mass fraction accumulated as accretion progresses.

therefore a good $\mathrm{fO}_{2}$ proxy during core formation. Mars and Vesta-4, for example, are considered to have differentiated under only moderately reducing conditions (IW and IW-1.5, respectively). This explains why SNC and HED meteorites display an almost chondritic $\mathrm{Nb} / \mathrm{Ta}$.

In summary, realistic Earth's core formation models are now in our reach that include a combination of a multistage core-mantle differentiation with N-body accretion simulations, or a continuous Earth's core formation where pressure, temperature and oxygen fugacity vary as the Earth's accretion proceed (e.g. Rubie et al., 2015a). In these models, we consider that the accretion of the Earth occurred during a series of large impact events (e.g. Canup, 2008; Wetherill, 1985; O'Brien et al., 2006; Monteux et al., 2009; Nakajima and Stevenson, 2015). The pressure and temperature of metal-silicate equilibrium likely increased as accretion progressed and core formation was therefore a continuous process. Other geochemical arguments based on ${ }^{107} \mathrm{Pd}-{ }^{107} \mathrm{Ag}$ and ${ }^{182} \mathrm{Hf}-{ }^{182} \mathrm{~W}$ (e.g. Halliday and Wood, 2009) provide support for continuous core formation. In addition, Wade and Wood (2005) completed the deep magma ocean model by presenting a model in which the magma ocean deepened in proportion to the size of the proto-Earth, and in which the Earth became more oxidized at the last accretion stages during the first $100 \mathrm{Ma}$. Results of both models suggest that accretion of Earth was heterogeneous with the initial $60-70 \%$ of Earth's mass forming from reducing material and the final $30-40 \%$ from relatively oxidized material. These models also give results for metal-silicate partitioning of a significant number of siderophile elements that are consistent with observed mantle abundances provided the oxygen fugacity increases from about IW-5 to IW-2 (5 to 2 log units lower than the Iron-Wüstite buffer) during core separation. This conclusion is consistent with $\mathrm{N}$-body simulations of terrestrial planet formation, which show that the Earth accreted material from farther from the sun at later times (e.g. Raymond et al., 2006; Morbidelli et al., 2012; Fischer and Ciela, 2014; Rubie et al., 2015a). Consequently, Earth began to accrete with a low FeO content in its mantle (in the range of 0.2-0.5 wt\% consistent with the reduced chondritic bodies as enstatite chondrites), and at the final stages of accretion we can assume that the Earth's core is $85 \mathrm{wt} \% \mathrm{Fe}$ and the mantle about $8 \mathrm{wt} \% \mathrm{FeO}$ (McDonough and Sun, 1995). Finally, for Earth the reducing material can be similar to enstatite chondrites as it is consistent with the ${ }^{17} \mathrm{O},{ }^{48} \mathrm{Ca},{ }^{50} \mathrm{Ti},{ }^{62} \mathrm{Ni}$ and ${ }^{90} \mathrm{Mo}$ isotopic study by Dauphas et al. (2014). Enstatite chondrites being the main building blocks of the Earth are also consistent with a recent collisional erosion model (Boujibar et al., 2015) or the separation of the core from a hydrous magma ocean (Clesi et al., 2016).
Other model suggests that the Earth's mantle can start in a highly oxidized state and becomes more reduced as FeO enters the core (Rubie et al., 2004; Siebert et al., 2013). However this type of model is only valid when no Si partitions into the Earth's core. Recent experiments show in fact the simultaneous incorporation of $\mathrm{Si}$ and $\mathrm{O}$ at the Earth's core formation conditions (Bouhifd and Jephcoat, 2011; Siebert et al., 2012; Tsuno et al., 2013; Fischer et al., 2015). Every mole of silicon that enters into the core releases two moles of FeO that partition into the mantle following the reaction (1), as proposed by Javoy (1995) and Javoy et al. (2010) to argue for an enstatite chondrite model for the Earth:

$2 \mathrm{Fe}_{(\text {metal })}+\mathrm{SiO}_{2 \text { (silicate) }}=\mathrm{Si}_{(\text {metal })}+2 \mathrm{FeO}_{(\text {silicate })}$

Consequently the initially oxidized mantle cannot be reduced to its present state when mass balance is taken into account (e.g. Rubie et al., 2015a).

\section{Incorporation of highly volatiles in an early magma ocean}

Highly volatile elements are defined as elements with low 50\% condensation temperature (lower than about $800 \mathrm{~K}$ at $10^{-4} \mathrm{~atm}-$ McDonough and Sun, 1995) and can include hydrogen, carbon, nitrogen, sulfur and noble gases. In the following we will only focus on helium, and how the solubility and partitioning of this element during Earth's core formation places strong constraints on the formation and evolution of our planet. For the other elements their behaviour during the earliest time of our planet can be found in recent papers - even if the origins and abundances of these elements are still much debated (e.g. Albarède, 2009; Armytage et al., 2013; Bergin et al., 2015; Boujibar et al., 2014; Dasgupta et al., 2013; Gaillard and Scaillet, 2014; Gaillard et al., 2015; Halliday, 2013; Hirschmann, 2016; Hirschmann and Dasgupta, 2009; Hirschmann et al., 2012; Jephcoat et al., 2008; Kadik et al., 2015; Li et al., 2016; Marty, 2012; Marty et al., 2013; Moreira, 2013; Mukhopadhayay, 2012; Roskosz et al., 2013; Wood et al., 2013; and references therein).

\subsection{Helium in early magma ocean}

To simulate Earth's core formation under conditions of segregation from a deep magma ocean, helium partitioning was determined in a mixture of a molten $\mathrm{CI}$-chondrite model composition and Fe-Ni metal alloy liquid (Bouhifd et al., 2013). The results presented in this study show that the concentrations of $\mathrm{He}$ in a $\mathrm{Cl}$-chondrite melt increase with increasing pressure up to $\sim 3 \mathrm{GPa}$, remain roughly constant in the range of 3 to $8 \mathrm{GPa}$ and drop from $2000 \mathrm{ppm}$ to about $500 \mathrm{ppm}$ and again remain constant to the maximum pressure reached of that work (of $\sim 16 \mathrm{GPa}$ ). One can note that the shape of He solubility in CI-chondrite melt versus pressure is similar to that observed for Ar with similar silicate composition (Bouhifd and Jephcoat, 2006). We reported in Fig. $4 \mathrm{a}-\mathrm{b}$ the $\mathrm{Ar}$ and He solubilities in $\mathrm{CI}$-chondrite melt at high pressures. Both studies indicate that below $8 \mathrm{GPa}$ (pressure corresponding to a drop of $\mathrm{Ar}$ and He solubilities in $\mathrm{CI}$-chondrite melt and corresponding to depths $<300 \mathrm{~km}$ in the Earth's mantle), Ar and He may dissolve in silicate melts formed by partial melting in the Earth's interior. In a study up to $8 \mathrm{GPa}$, the partition coefficient of Ar between clinopyroxene and its melt was found to be between $10^{-3}$ and $10^{-4}$, implying that $\mathrm{He}$ and $\mathrm{Ar}$ would be partitioned in melt and also ultimately degassed (Brooker et al., 2003). This behaviour indicates that Ar and He maintain their geochemically assumed incompatible behaviour with crystalline phases. Similar conclusion can be drawn from experiments at $0.1 \mathrm{GPa}$ where all noble gases show an incompatible behaviour for olivine and clinopyroxene (Heber et al., 2007). However, the high-pressure step decrease of $\mathrm{Ar}$ and $\mathrm{He}$ in $\mathrm{CI}$-chondrite melt observed at about $8 \mathrm{GPa}$ implies that there may be an increase in compatibility with the crystalline phase (assuming that the crystalline phase does not undergo similar drop in solubility at high pressures). At depths for pressures $>8 \mathrm{GPa}(\sim 300 \mathrm{~km}$ 

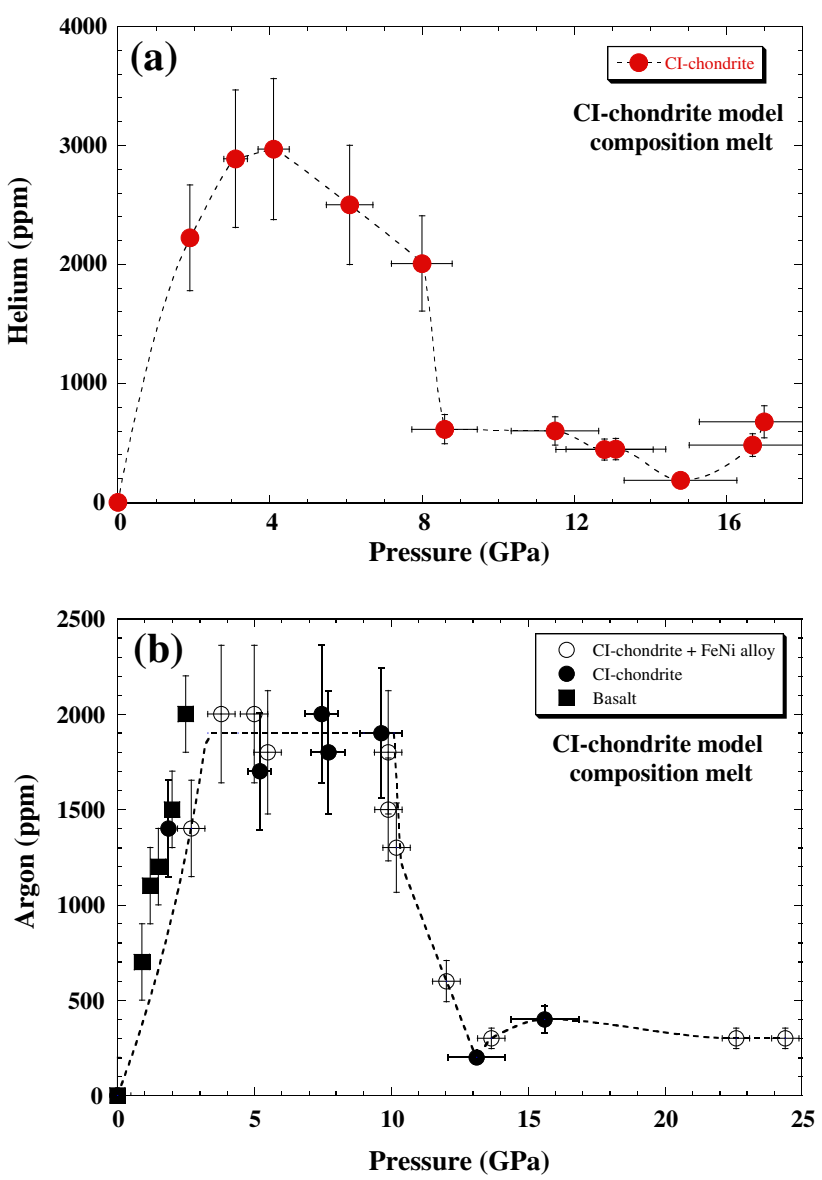

Fig. 4. (a) Helium concentrations ( $\mathrm{ppm}$ ) in Cl-chondrite melt as a function of pressure (GPa). Figure taken from Bouhifd et al. (2013). (b) Argon concentrations (ppm) in CIchondrite melt as a function of pressure (GPa). Data are taken from Bouhifd and Jephcoat (2006), Bouhifd et al. (2008) and White et al. (1989). For both figures error bars correspond to $1 \sigma$ (ranging from 7 to $25 \%$ ) of the average of the chemical analysis and to $10 \%$ of the nominal pressures reported. The dashed lines are used as a guide line only.

in the Earth's mantle) the Ar and He solubility in CI-chondrite melt indicates that it would be possible for primordial and radiogenic $\mathrm{Ar}$ and $\mathrm{He}$ to be preferentially retained deep in the Earth. One can note here that the solubility of $\mathrm{Ar}$ in silicate melts at high pressure is an ongoing debate as the solubility drop of $\mathrm{Ar}$ in $\mathrm{SiO}_{2}$ melt at about $5 \mathrm{GPa}$ (Chamorro-Perez et al., 1996; Bouhifd et al., 2008) was not reproduced in a recent study by Niwa et al. (2013), who instead show a slight decrease of Ar solubility in the range of 5-12 GPa. For basaltic melt, molecular dynamic simulations show also a slight decrease of Ar solubility in the range of 5 to $20 \mathrm{GPa}$ (Guillot and Sator, 2012), but such calculations present large uncertainties. In any case, for silicate melts, it is widely accepted that noble gases dissolve into the interstitial sites, meaning that their solubility is related to the concentration of holes able to accommodate atoms of particular size (Doremus, 1966; Studt et al., 1970; Shackelford et al., 1972; Shelby, 1976). Increasing pressure causes a continuous densification of melts leading to changes in the silicate units/species distribution within the silicate melt. In their molecular dynamics simulations of molten anorthite, Nevins and Spera (1998) show that near 5 GPa the activation volumes of all species present in the melt are higher in absolute value than the partial molar volume of Ar, meaning that Ar can still be accommodated in molten anorthite at this pressure. However, above $20 \mathrm{GPa}$ the activation volumes of all melt species drop below the partial molar volume of argon. This pressure is very consistent with the onset pressure of Ar solubility drop for anorthite liquid of about $17 \mathrm{GPa}$ (Bouhifd and Jephcoat, 2006). Thus, a first-order interpretation of the drop in Ar solubility data is that they represent a closing of a characteristic void space in melts at high pressures and temperatures.

\subsection{Earth's core as a reservoir for primordial helium}

The question now is whether the Earth's core could plausibly be a reservoir for helium, knowing that a large impact that formed the Moon may have depleted the mantle as well as the atmosphere from the noble gases by about 2 orders of magnitude. In fact, Xe isotopes indicate that extensive loss ( $>97 \%$ ) occurred from the mantle and atmosphere at two episodes of major mantle degassing, presumably driven by giant impacts, respectively at 20-50 Ma and about $100 \mathrm{Ma}$ after the formation of the solar system which is consistent with the timing of Moon formation derived from Hf-W systematics and simulations of the giant impact (Pepin and Porcelli, 2006; Porcelli et al., 2001). Helium concentration in the early Earth's core was controlled by the initial He abundance in the early mantle at the time of core formation. High mantle concentrations of noble gases may have existed in the early mantle even if the mechanism by which early Earth acquired its noble gases is still debated. Noble gases in the early Earth's mantle can have two main origins: (1) the first origin/mechanism is the dissolution of gases from a dense, gravitationally captured atmosphere (assuming the Earth reached much of its present mass before dissipation of the solar nebula) and convected into the mantle. In this scenario, noble gases of solar composition, in particular solar-type helium and neon are dissolved from the atmosphere (e.g. Harper and Jacobsen, 1996; Honda et al., 1991; Mizuno et al., 1980). (2) The second scenario is that mantle noble gases are already present in the parent bodies of the Earth, due to irradiation by the solar wind of refractory grains (e.g. Moreira, 2013; Moreira and Charnoz, 2016; Porcelli and Halliday, 2001; and references therein). Such mechanisms can provide at a minimum $7 \times 10^{12}$ atoms ${ }^{3} \mathrm{He} \mathrm{g}^{-1}$ in the mantle (Mizuno et al., 1980; Porcelli and Ballentine, 2002; Porcelli and Halliday, 2001; Trieloff and Kunz, 2005). Considering this value as the initial ${ }^{3} \mathrm{He}$ abundance during the Earth's core formation, and the measured molten metal - silicate liquid partition coefficients of $\mathrm{He}\left(D_{\mathrm{He}}\right)$ that range from about $5 \times 10^{-3}$ to $2 \times 10^{-2}$ at high pressure and high temperature (Bouhifd et al., 2013; Zhang and Yin, 2012), the early Earth's core would contains between $3 \times 10^{10}$ and $1.2 \times 10^{113} \mathrm{Heatoms}^{-1}$. 1. On the other hand, the ${ }^{3} \mathrm{He}$ flux from Oceanic Island Basalts (OIB) ranges from about 38 to $1000 \mathrm{~mol} \mathrm{yr}^{-1}$ equivalent to values from about

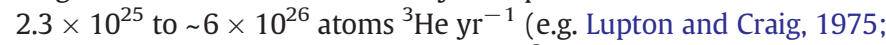
Porcelli and Ballentine, 2002). The ratio of ${ }^{3} \mathrm{He}$ flux from OIB to the concentrations of ${ }^{3} \mathrm{He}$ in the Earth's core requires that 0.8 to $3 \%$ of the mass of the core should have released its primordial helium (Bouhifd et al., 2013). The range of ${ }^{3} \mathrm{He} /{ }^{4} \mathrm{He}$ ratios observed in the present day OIB samples would then be the result of mixing from the core with radiogenic ${ }^{4} \mathrm{He}$ and residual ${ }^{3} \mathrm{He}$ from the mantle. In addition, the early core would probably have formed with a high $\mathrm{He} / \mathrm{U}$ ratio because $\mathrm{U}$ is a highly lithophile element (Wheeler et al., 2006; Malavergne et al., 2007; Bouhifd et al., 2013), and the core probably maintained a high, throughout Earth's history, ${ }^{3} \mathrm{He} /{ }^{4} \mathrm{He}$ ratio. The mantle reservoir debate (at least for helium - more similar work is needed for other noble gases) must now include exchange processes that operate at the core-mantle boundary, especially when molten metal - silicate melt reactions are involved (e.g. Herzberg et al., 2013), and knowing, as reported by Macpherson et al. (1998) that high ${ }^{3} \mathrm{He} /{ }^{4} \mathrm{He}$ coincides with a domain of ULZV usually associated with partial melting of silicates directly above a molten core. Finally, even if the core helium budget is actually sufficient to provide all mantle ${ }^{3} \mathrm{He}$, it is reasonable to expect that only OIBs originating from the core-mantle boundary can carry the high ${ }^{3} \mathrm{He}-{ }^{4} \mathrm{He}$ core signature, making the Earth's core a plausible reservoir for these high ${ }^{3} \mathrm{He}-{ }^{4} \mathrm{He}$ ratios.

\section{Magma ocean crystallization after core formation}

After the core-mantle separation, a second major chemical differentiation event occurred during the magma ocean crystallization. Indeed, during the cooling and the subsequent solidification of the magma 
ocean, compatible elements (e.g. $\mathrm{Mg}, \mathrm{Cr}$ ) were preferentially collected in the solid phase while the incompatible elements (e.g. Al, Na, Fe) selectively partitioned into melts. Depending on the density contrast between the solid and the ambient liquid, a major chemical separation occurred within the early mantle. This differentiation event was strongly influenced by the cooling processes that governed the rheology, the melt fraction and hence the efficiency of chemical exchanges within the solidifying early mantle. As the melt fraction depends on the distance between the solidus and liquidus of the mantle, the melting curves of the primitive mantle have major consequences on the cooling dynamics of the early mantle, on the existence of chemical heterogeneities and on their lifetime within primitive mantle reservoirs. Until recently, the determination of melting properties of samples was rather limited in pressure. Now systematic experimental determinations of the solidus and liquidus of geological materials are determined up to the core-mantle boundary (CMB) using the laser-heated diamond anvil cell technique (LHDAC) (e.g. Fiquet et al., 2010; Andrault et al., 2011, 2014; Nomura et al., 2014; Tateno et al., 2014; Pradhan et al., 2015). In Fig. 5 we report the liquidus and solidus of chondritic mantle (the details about the determination of the liquidus and solidus of chondritic material - that are beyond the scope of the present work - are reported in Andrault et al., 2011).

In vigorously convecting systems such as magma oceans, the temperature distribution is nearly adiabatic and isentropic and the crystallization is supposed to start as soon as the adiabatic profile is crossing the liquidus (e.g. Solomatov, 2007). In one-phase systems, such as a completely molten or a completely solid layer, the equation for an adiabat is

$\left(\frac{\partial T}{\partial r}\right)_{S}=-\frac{\alpha g}{C_{p}} T$

where $T$ is the temperature, $r$ is radius and $g$ is the gravitational acceleration. $\rho, \alpha$ and $C_{p}$ are respectively the density, the coefficient of volumetric thermal expansion and the specific heat of the considered one phase material at a given depth.

In two-phase systems, the effects of phase changes need to be considered (Solomatov, 2007). For a zone of partial melting, the density $\rho^{\prime}$, the coefficient of volumetric thermal expansion $\alpha^{\prime}$ and the specific heat $C_{p}^{\prime}$ of the partially molten material are given as follows:

$\frac{1}{\rho^{\prime}}=\frac{1-\phi}{\rho_{s}}+\frac{\phi}{\rho_{m}}$

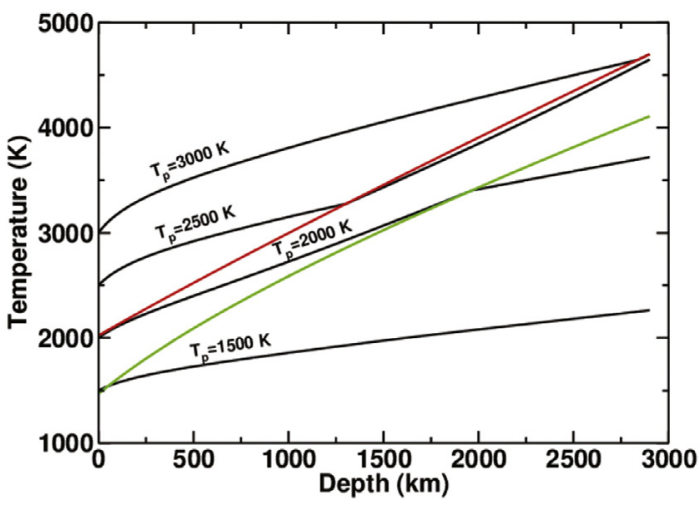

Fig. 5. Adiabatic profiles (black solid lines computed from Thomas and Asimow, 2013), solidus (green) and liquidus (red) (from Andrault et al., 2011) considering a chondritic composition for the early mantle. In this context, as the adiabats are steeper than the liquidus in the whole mantle, an initially fully molten mantle will start to solidify from the core-mantle boundary toward the Earth's surface. (For interpretation of the references to colour in this figure legend, the reader is referred to the web version of this article.)

$$
\begin{aligned}
& \alpha^{\prime}=\alpha+\frac{\Delta \rho}{\rho^{\prime}\left(T_{\text {liq }}-T_{\text {sol }}\right)} \\
& C^{\prime} p=C_{p}+\frac{\Delta H}{T_{\text {liq }}-T_{\text {sol }}}
\end{aligned}
$$

where $\phi$ is the melt fraction at a given depth, $\rho_{s}$ is the density of the solid phase, $\rho_{m}$ is the density of the molten phase, $\Delta \rho$ is the density difference between solid and liquid. $T_{\text {liq }}$ and $T_{\text {sol }}$ are the liquidus and solidus temperature at a given depth. $\Delta H$ is the latent heat released during solidification. The equation for such adiabats is given by:

$$
\left(\frac{\partial T}{\partial r}\right)_{S}=-\frac{\alpha^{\prime} g}{C_{p}^{\prime}} T
$$

The thermodynamical parameters for the molten magma ocean are closely related to its chemical composition. Volume and elastic parameters of silicate liquids have been recently characterized up to $140 \mathrm{GPa}$ using shock compression experiments (Mosenfelder et al., 2007, 2009; Thomas et al., 2012; Thomas and Asimow, 2013). In Fig. 5 we also reported the adiabats computed from Thomas and Asimow (2013) considering a chondritic composition for the early mantle. The adiabatic temperature profiles are calculated by numerical integration of Eqs. (1) and (5) using a fourth-order Runge-Kutta method (Press et al., 1993). We assumed here a multi-component system with a chondritic composition $(62 \%$ enstatite $+24 \%$ forsterite $+8 \%$ fayalite $+4 \%$ anorthite $+2 \%$ diopside). Using fourth-order Birch-Murnaghan/MieGrüneisen equation of state fits for molten silicate liquids from Thomas and Asimow (2013), we obtained the melt density $\rho_{m}$, the volumetric thermal expansion $\alpha$ as a function of pressure as well as the specific heat $C_{p}$ of the molten material for this multicomponent assemblage (see Monteux et al., 2016 for more details). Fig. 5 illustrates that a chondritic two-phase adiabat is steeper than the purely liquid or solid one-phase chondritic adiabats (Solomatov, 2007).

Depending on the slope difference between the adiabats and the liquidus, the crystallization will occur either from the bottom toward the surface or from the top toward the bottom (e.g. Solomatov, 2007; Labrosse et al., 2007; Monteux et al., 2016). Hence, determining precisely the adiabatic profiles within the magma ocean is also a key aspect to constrain the thermo-chemical evolution of the early terrestrial mantle (Thomas and Asimow, 2013). When the melt fraction of the magma ocean decreases down to a critical value of $40 \%$ the cooling dynamics are not governed by the liquid phase but by the solid phase (Abe, 1997). Upon cooling, both the solid and liquid compositions will diverge from the early mantle composition. The density contrast between the liquid and solid phases may lead to a separation between the two phases as a consequence of crystal sedimentation and/or transcrystalline migration of the liquid (e.g. Schiano et al., 2006). This differentiation may lead to the separation between compatible elements that will easily reach the solid phase (e.g. $\mathrm{Mg}, \mathrm{Cr}$ ) while the incompatible elements will remain in the liquid phase (e.g. Al, Na, Fe). The density contrast will affect the chemical segregation and, hence, the geodynamical consequences will differ depending if the buoyancy between the two phases is positive or negative even if the vigor of the convection will potentially erase the chemical contrasts. The ascent or descent of the liquid phase within the partially molten mantle will either contribute to early volcanism or to the formation of a dense basal magma ocean. This aspect is currently under debate: Nomura et al. (2011) suggest an iron rich liquid phase denser than the mantle while Andrault et al. (2012) suggest a buoyant liquid phase that, as a consequence, leads to the formation of a deep residual layer enriched in compatible elements. 


\subsection{Implications for the magma ocean during accretion}

The observations of a high liquidus temperature for a chondritic mantle as well as a large gap between its solidus and liquidus temperatures have important implications for the properties of the magma ocean during accretion. As reported in Fig. 5, a fully molten chondritic mantle that would extend to a pressure range of 40-60 GPa (pressure/ depth of magma ocean range derived from siderophile elements) exhibits temperatures in the range of 3000-3500 K (e.g. Bouhifd and Jephcoat, 2011; Righter, 2011; Siebert et al., 2012; Fischer et al., 2015). Such conditions correspond to a surface potential temperature of about $2500 \mathrm{~K}$ (e.g. Andrault et al., 2011). Such a hot surface is not stable and is only compatible with a transient magma ocean. In fact, surface temperatures higher than $1800 \mathrm{~K}$ prevent formation of an $\left(\mathrm{H}_{2} \mathrm{O}-\mathrm{CO}_{2}\right)$ rich atmosphere required to produce an efficient thermal blanket to the magma ocean (Abe and Matsui, 1988; Zahnle et al., 1988). Above $1800 \mathrm{~K}$, it appears that significant silicate vaporization occurs, and such rock vapor atmosphere conducts heat easily so that the magma ocean would cool down in a few thousand years (Nagahara and Ozawa, 1996; Sleep et al., 2001). A conclusion of transient magma ocean during the first $100 \mathrm{Ma}$ of Earth's history drawn from melting curves of chondritic mantle is consistent with geochemical evidence (Tucker and Mukhopadhyay, 2014). In this latter study, the authors present evidence for at least two separate magma ocean episodes on early Earth based on the ratio of primordial ${ }^{3} \mathrm{He}$ and ${ }^{22} \mathrm{Ne}$ in the present-day mantle.

\subsection{Role on mantle chemical heterogeneities}

As noted above the abundance of moderately siderophile elements in the Earth's mantle are better explained with scenarios where the pressure and temperature of core-mantle equilibration increase with time (e.g. Wood et al., 2006; Fischer et al., 2015), hence where the magma ocean's floor deepened throughout Earth's accretion. In the majority of these core-segregation models, the magma ocean floor is located at half or $2 / 3$ of the depth of the core-mantle boundary, which increases progressively on the course of the accretion (e.g. Wade and Wood, 2005; Rubie et al., 2015a; Fischer et al., 2015). This implies that as soon as the Earth achieved about $~ 30 \%$ of its present-day mass, the floor of the magma ocean reached a pressure sufficient to enter the stability domain of bridgmanite (Al-bearing $(\mathrm{Mg}, \mathrm{Fe}) \mathrm{SiO}_{3}$ with perovskitetype structure, $\mathrm{Bg}$ ). Therefore, the equilibration between magmaocean, Bg-rich solid mantle and segregating metallic phases, may have had an important role during Earth's differentiation.

Archean rocks show anomalies of ${ }^{142} \mathrm{Nd}$ in comparison to modern samples, which suggests an early differentiation of the primitive mantle through early decay of the extinct radionuclide ${ }^{146} \mathrm{Sm}$ (Boyet and Carlson, 2006; Caro et al., 2006; Rizo et al., 2013). The strong fractionation between $\mathrm{Sm}$ and $\mathrm{Nd}$ required for explaining these isotopic anomalies support a scenario of a magma ocean at $\sim 4.47 \mathrm{Ga}$ (Rizo et al., 2011). The modern terrestrial samples show relatively homogeneous ${ }^{142} \mathrm{Nd} /{ }^{144} \mathrm{Nd}$ ratios, resulting from efficient mantle convection and mixing of the early-formed enriched and depleted reservoirs. This constant isotopic ratio recorded by samples from the surface is however higher than those measured in the majority of chondrites, with the exception of some enstatite chondrites (Gannoun et al., 2011). The question of the starting material for modeling the long-term evolution of the silicate Earth is essential. Although none of the chondrite group known so far seems to reproduce exactly the terrestrial composition, enstatite chondrites are closest to Earth's composition when looking at the abundance of ${ }^{142} \mathrm{Nd}$ and of many other refractory elements (Warren, 2011). The stable Nd isotopic composition of terrestrial samples is different from that of carbonaceous and ordinary chondrites (Carlson et al., 2007; Burkhardt et al., 2016). This suggests that the ${ }^{142} \mathrm{Nd}$ difference is not due to the ${ }^{146} \mathrm{Sm}$ decay but was caused by isotopic variation imparted during the formation of Solar System. For enstatite chondrites, the difference is more elusive since their stable $\mathrm{Nd}$ isotopic composition are within the terrestrial field considering the analytical error and that they have $10 \mathrm{ppm}$ deficit in ${ }^{142} \mathrm{Nd}$ relative to the Earth. If Earth is mainly made by enstatite chondrites, the calculated ${ }^{147} \mathrm{Sm} /{ }^{144} \mathrm{Nd}$ ratio of the silicate Earth would be 0.200 , which is $2 \%$ higher than the average chondritic ${ }^{147} \mathrm{Sm} /{ }^{144} \mathrm{Nd}$ ratio and within the range of values previously measured for whole-rock chondrites. Bouvier and Boyet (2016) have also identified primitive Solar System material (calcium-aluminium-rich refractory inlcusions) without isotopic anomalies in Nd compared to the terrestrial composition but this type of material cannot have formed Earth. Therefore, the preservation of an unsampled or hidden reservoir due to early differentiation from magma ocean crystallization is still a conceivable hypothesis but the volume is probably more reduced than estimates proposed by Boyet and Carlson (2005). As a matter of fact, seismic tomography showed the presence of anomalously high seismic velocities at the D" layer, that can be interpreted in several ways, including the occurrence of partial melts, enriched in incompatible elements and representing leftovers from an ancient basal magma ocean, in a scenario where the magma ocean is crystallizing from the mid-lower mantle (Labrosse et al., 2007). The recent discovery of large excesses of ${ }^{182} \mathrm{~W}$ that seems to be correlated to high ${ }^{3} \mathrm{He} /{ }^{4} \mathrm{He}$ ratios in modern flood basalts indicates long-term preservation of $\mathrm{W}$ isotopic signatures formed in the first $50 \mathrm{Ma}$ of Earth's history (Rizo et al., 2016). The notoriety of this undegassed hidden reservoir hypothesis is typically due to the fact that it can resolve several geochemical paradoxes such as the noble gas isotopic signatures (Coltice et al., 2011).

In fact, a remarkable feature of the core-mantle boundary is the existence of ULVZs (Ultra Low Velocity Zones). The ULVZs are characterized by $S$ - and $P$ - seismic velocity reductions and are usually associated with partial melting of silicates directly above the core (Williams and Garnero, 1996; Revenaugh and Meyer, 1997; Vidale and Hedlin, 1998; Lay et al., 2004; Rost et al., 2005) although alternative interpretations are possible: solid-state origin (Fe-enriched ( $\mathrm{Mg}, \mathrm{Fe}) \mathrm{O}$ ) (e.g. Wicks et al., 2010; Bower et al., 2011; Brown et al., 2015) or accumulated sediments on top of the Earth's core (Buffett et al., 2000). More details on the origin of the ULVZs can also be found in the review papers by Tackley (2012) or Carlson et al. (2014).

In order to trap and isolate enriched melts deep at the CMB, their density should stay higher than the solid mantle. Two recent experimental studies aimed at determining the density contrast between $\mathrm{Bg}$ and silicate melt by measuring the partition coefficients of Fe between $\mathrm{Bg}$ and melt $\left(\mathrm{D}_{\mathrm{Fe}}^{\mathrm{Bg} / \text { melt }}\right)$ at various pressures, down to $\mathrm{CMB}$ conditions (Andrault et al., 2012; Nomura et al., 2011). These studies provided contrasting results where $\mathrm{D}_{\mathrm{Fe}}^{\mathrm{Bg} / \text { melt }}$ was of 0.2-0.3 in Nomura et al. (2011) and Tateno et al. (2014) and 0.5-0.6 in Andrault et al. (2012), leading to contradictory interpretations for the fate of deep silicate melts, which are either denser or more buoyant than the solid silicate. A recent study conducted at fixed pressure (25 GPa) has proposed another explanation to this controversy, showing that the degree of melting $(F)$ can significantly vary $\mathrm{D}_{\mathrm{Fe}}^{\mathrm{Bg} / \text { melt }}$ (Boujibar et al., 2016). This study shows that at $25 \mathrm{GPa}, \mathrm{D}_{\mathrm{Fe}}^{\mathrm{Bg} / \text { melt }}$ is close to 1 at extremely low degree of melting and becomes constant and equaling $0.3 \pm 0.1$ when $\mathrm{F}$ is higher than $10 \%$. Therefore, the degree of melting is another parameter that should be taken into account in order to address mantle dynamics and the fate of a molten enriched reservoir at the base of the lower mantle.

\subsection{Role on the redox state of the mantle}

Several studies have previously proposed that Bg crystallization had major effects on the redox state of the mantle (Frost et al., 2004; Wood et al., 2006). Bg has the ability to integrate high levels of $\mathrm{Fe}^{3+}$ in its structure. In particular, it was previously shown that the presence of Al enhances the incorporation of $\mathrm{Fe}^{3+}$, owing to the coupled substitution of $\mathrm{Al}$ and $\mathrm{Fe}^{3+}$ for $\mathrm{Mg}$ and $\mathrm{Si}$ in their respective dodecahedral and octahedral sites (Andrault et al., 2007; Lauterbach et al., 2000). This 
substitution mechanism is so stable that it was suggested to force $\mathrm{Fe}^{2+}$ to disproportionate into $\mathrm{Fe}^{3+}$ and $\mathrm{Fe}^{0}$ through the reaction:

$3 \mathrm{Fe}^{2+}=\mathrm{Fe}^{0}+2 \mathrm{Fe}^{3+}$

Therefore, since the magma ocean's floor reached a depth sufficiently high to crystallize Bg, the magma ocean/solid mantle boundary was presumably acting as an oxygen pump, where $\mathrm{Fe}^{3+}$ was stabilized in $\mathrm{Bg}$ and progressively released to the magma ocean, while $\mathrm{Fe}^{0}$ was systematically trapped in the solid lower mantle and subsequently falling to the core. Therefore the crystallization of the magma ocean was considered as a plausible mechanism for raising the oxygen state of the Earth's mantle (Wade and Wood, 2005). This idea was based on the fact that Al-content increases the solubility of $\mathrm{Fe}^{3+}$ in $\mathrm{Bg}$ independently from the oxygen fugacity (Frost et al., 2004; Frost and Langenhorst, 2002). However recent experimental studies showed that the oxygen fugacity (nature of the starting composition or capsule material) has an important effect on $\mathrm{Fe}^{3+}$ incorporation in $\mathrm{Bg}$ (Nakajima et al., 2012; Boujibar et al., 2016). In particular, recent experimental data on equilibrium between $\mathrm{Bg}$, silicate melt and liquid metal showed that at an $f_{\mathrm{O} 2}$ of $\sim \mathrm{IW}-2$ (2 log units below IW buffer), the $\mathrm{Fe}^{3+}$-content in $\mathrm{Bg}$ is relatively low ( $20 \%)$ and weakly dependent on the Al-content. Aluminium starts having an important positive effect on $\mathrm{Fe}^{3+}$ in $\mathrm{Bg}$ only when the oxygen fugacity is higher than $\sim$ IW-1 to IW (Fig. 6) (Boujibar et al., 2016). These results are challenging previous planetary differentiation models and imply that Bg crystallization during the cooling of the magma ocean can only have a substantial effect on the redox state of the mantle after the end of core segregation. Given that the final $\mathrm{fO}_{2}$ equilibration between core and mantle is about IW-2 (based on present-day $\mathrm{FeO}$ content of the mantle of $\sim 8 \mathrm{wt} \%$ and on the $85 \mathrm{wt} \%$ Fe of the core, estimated from the Earth's core density deficit), one can conclude that any increase of the Earth's redox state before the completion of core segregation should originate from other mechanisms than Bg crystallization from the magma ocean.

\section{Concluding remarks}

Earth's core formation models that include a combination of a multistage core-mantle differentiation with $\mathrm{N}$-body accretion simulations lead to coherent view of the early history of our planet. The actual models suggest that accretion of Earth was heterogeneous with the

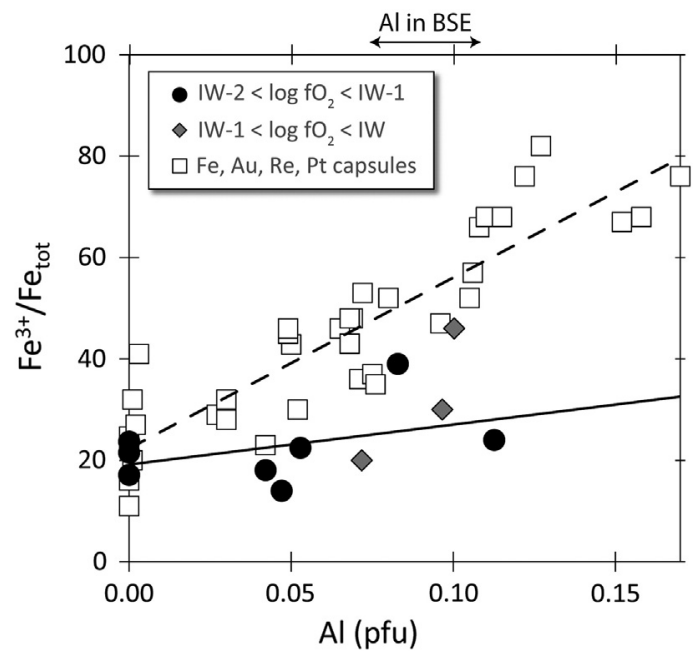

Fig. 6. $\mathrm{Fe}^{3+} / \sum \mathrm{Fe}$ in bridgmanite as a function of Al-content for different $f_{\mathrm{O} 2}$ conditions ranging from IW-2 to IW-1 (black circles) (Boujibar et al., 2016; Terasaki et al., 2007; Frost et al., 2004), IW-1 to IW (gray diamonds) (Frost et al., 2004) and close or higher than IW buffer (where capsule material was metallic Fe, Au, Re or Pt) (Frost and Langenhorst, 2002; Frost et al., 2004; Lauterbach et al., 2000; McCammon et al., 2004; Saikia et al., 2009). initial $60-70 \%$ of Earth's mass forming from reducing material and the final $30-40 \%$ from relatively oxidized material. In addition, the available observations point to the occurrence of magma oceans in the early evolution of terrestrial planets. By applying this scenario we found that the Earth's core is a plausible reservoir for primordial helium. It is also possible to match the observed subchondritic $\mathrm{Nb} / \mathrm{Ta}$ ratio of the bulk silicate Earth, highlighting that planetary accretion of reduced materials played an important role in the chemical evolution of Earth, and more general$\mathrm{ly}$, that $\mathrm{Nb} / \mathrm{Ta}$ ratio can be used to trace prevailing oxygen fugacities during the segregation of planetary cores.

The available experiments of a high liquidus temperature for a chondritic mantle, as well as observations based on the ratio of primordial helium and neon isotopes, lead to a conclusion of transient magma ocean during the first $100 \mathrm{Ma}$ of Earth's history. At least two separate magma ocean episodes on early Earth are suggested from noble gases isotopes.

To solve the existing controversy about the partitioning of Fe between bridgmanite and silicate melt, it seems that the degree of melting should be taken into account in order to address mantle dynamics and the fate of a molten enriched reservoir at the base of the lower mantle.

\section{Acknowledgments}

This paper was presented in the 10th Silicate Melt Worshop - La Petite Pierre. We thank Don Dingwell, Kai Uwe Hess and Pascal Richet for the organization of the workshop and for being the guest editors of this special issue. Part of this work was funded by the CNRS-INSU (program: PNP), ANR (project: Oxy-Deep), and ERC (project: ISOREE). This research was also financed by the French Government Laboratory of Excellence initiative $\mathrm{n}^{\circ}$ ANR-10-LABX-0006, the Région Auvergne and the European Regional Development Fund. This is Laboratory of Excellence ClerVolc contribution number 231.

\section{References}

Abe, Y., 1997. Thermal and chemical evolution of the terrestrial magma ocean. Phys. Earth Planet. Inter. 100, 27-39.

Abe, Y., Matsui, T., 1988. Evolution of an impact-generated $\mathrm{H}_{2} \mathrm{O}-\mathrm{CO}_{2}$ atmosphere and formation of a hot proto-ocean on Earth. J. Atmos. Sci. 45, 3081-3101.

Albarède, F., 2009. Volatile accretion history of the terrestrial planets and dynamic implications. Nature 461, 1227-1233.

Allègre, C.J., Staudacher, T., Sarda, P., Kurz, M., 1983. Constraints on evolution of Earth's mantle from rare gas systematics. Nature 303, 762-766.

Amelin, Y., Krot, A.N., Hutcheon, I.D., Ulyanov, A.A., 2002. Lead isotopic ages of chondrules and calcium-aluminium-rich inclusions. Science 297, 1678-1683.

Andrault, D., Bolfan-Casanova, N., Bouhifd, M.A., Guignot, N., Kawamoto, T., 2007. The role of Al-defects on the equation of state of $\mathrm{Al}-(\mathrm{Mg}, \mathrm{Fe}) \mathrm{SiO}_{3}$ perovskite. Earth Planet. Sci. Lett. 263, 167-179.

Andrault, D., Bolfan-Casanova, N., Lo Nigro, G., Bouhifd, M.A., Garbarino, G., Mezouar, M., 2011. Solidus and liquidus profiles of chondritic mantle: implication for melting of the Earth across its history. Earth Planet. Sci. Lett. 304, 251-259.

Andrault, D., Petitgirard, S., Lo Nigro, G., Devidal, J.-L., Veronesi, G., Garbarino, G., Mezouar, M., 2012. Solid-liquid iron partitioning in Earth's deep mantle. Nature 487, 354-357.

Andrault, D., Pesce, G., Bouhifd, M.A., Bolfan-Casanova, N., Hénot, J.-M., Mezouar, M., 2014. Melting of subducted basalt at the core-mantle boundary. Science 344, 892-895.

Armytage, R., Jephcoat, A.P., Bouhifd, M.A., Porcelli, D., 2013. Metal-silicate partitioning of iodine at high pressures and temperatures: implications for the Earth's core and ${ }^{129}$ Xe budgets. Earth Planet. Sci. Lett. 373, 140-149.

Bajgain, S., Ghosh, D.B., Karki, B.B., 2015. Structure and density of basaltic melts at mantle conditions from first-principles simulations. Nat. Commun. 6:8578. http://dx.doi.org/ 10.1038/ncomms9578.

Bergin, E.A., Blake, G.A., Ciesla, F., Hirschmann, M.M., Li, J., 2015. Tracing the ingredients for a habitable Earth from interstellar space through planet formation. Proc. Natl. Acad. Sci. 112, 8965-8970.

Bouhifd, M.A., Jephcoat, A.P., 2003. The effect of pressure on partitioning of Ni and Co between silicate and iron-rich metal liquids: a diamond-anvil cell study. Earth Planet. Sci. Lett. 209, 245-255.

Bouhifd, M.A., Jephcoat, A.P., 2006. Aluminium control of argon solubility in silicate melts under pressure. Nature 439, 961-964

Bouhifd, M.A., Jephcoat, A.P., 2011. Convergence of Ni and Co metal-silicate partition coefficients in the deep magma-ocean and light-elements core solubility at high pressures. Earth Planet. Sci. Lett. 307, 341-348.

Bouhifd, M.A., Jephcoat, A.P., Kelley, S.P., 2008. Argon solubility drop in silicate melts at high pressures: a review of recent experiments. Chem. Geol. 256, 252-258.

Bouhifd, M.A., Jephcoat, A.P., Heber, V.S., Kelley, S.P., 2013. Helium in an early Earth's core. Nat. Geosci. 6, 982-986. 
Bouhifd, M.A., Boyet, M., Cartier, C., Hammouda, T., Bolfan-Casanova, N., Devidal, J.L., Andrault, D., 2015. Superchondritic Sm/Nd ratio of the Earth: impact of Earth's core formation. Earth Planet. Sci. Lett. 413, 158-166.

Boujibar, A., Andrault, D., Bouhifd, M.A., Bolfan-Casanova, N., Devidal, J.L., Trcera, N., 2014. Metal-silicate partitioning of sulfur, new experimental and thermodynamical constraints on planetary accretion. Earth Planet. Sci. Lett. 391, 42-54.

Boujibar, A., Andrault, D., Bolfan-Casanova, N., Bouhifd, M.A., Monteux, J., 2015. Cosmochemical fractionation by collisional erosion during the Earth's accretion. Nat. Commun. 6:8295. http://dx.doi.org/10.1038/ncomms9295.

Boujibar, A., Bolfan-Casanova, N., Andrault, D., Bouhifd, M.A., Trcera, N., 2016. Incorporation of $\mathrm{Fe}^{2+}$ and $\mathrm{Fe}^{3+}$ in bridgmanite during magma ocean crystallization. Am. Mineral. 101, 1560-1570.

Bouvier, A., Boyet, M., 2016. Primitive solar system materials and Earth share a common initial ${ }^{142} \mathrm{Nd}$ abundance. Nature 537, 399-402.

Bouvier, A., Wadhwa, M., 2010. The age of the solar system redefined by the oldest $\mathrm{Pb}-\mathrm{Pb}$ age of a meteoritic inclusion. Nat. Geosci. 3, 637-641.

Bower, D.J., Wicks, J.K., Gurnis, M., Jackson, J.M., 2011. A geodynamic and mineral physics model of a solid-state ultralow-velocity zone. Earth Planet. Sci. Lett. 303, 193-202.

Boyet, M., Carlson, R.W., 2005. ${ }^{142} \mathrm{Nd}$ evidence for early (>4.53 Ga) global differentiation of the silicate Earth. Science 309, 576-581.

Boyet, M., Carlson, R.W., 2006. A new geochemical model for the Earth's mantle inferred from ${ }^{146} \mathrm{Sm}^{142} \mathrm{Nd}$ systematics. Earth Planet. Sci. Lett. 250, 254-268.

Boyet, M., Carlson, R.W., Borg, L.E., Horan, M., 2015. Sm-Nd systematics of lunar ferroan anorthositic suite rocks: constraints on lunar crust formation. Geochim. Cosmochim. Acta $148,203-218$

Brennecka, G.A., Wadhwa, M., 2012. Uranium isotope compositions of the basaltic angrite meteorites and the chronological implications for the early Solar System. Proc. Natl. Acad. Sci. U. S. A. 109, 9299-9303.

Brooker, R.A., Du, Z., Blundy, J.D., Kelley, S.P., Allan, N.L., Wood, B.J., Chamorro, E.M., Wartho, J.A., Purton, J.A., 2003. The "zero charge" partitioning behaviour of noble gases during mantle melting. Nature 423, 738-741.

Brown, S.P., Thorne, M.S., Miyagi, L., Rost, S., 2015. A compositional origin to ultralow velocity zones. Geophys. Res. Lett. 42:1039-1045. http://dx.doi.org/10.1002/ 2014 GL062097.

Buffett, B.A., Garnero, E.J., Jeanloz, R., 2000. Sediments at the top of Earth's core. Science 290, 1338-1342.

Burkhardt, C., Borg, L.E., Brennecka, G.A., Shollenberger, Q.R., Dauphas, N., Kleine, T., 2016 A nucleosynthetic origin for the Earth's anomalous ${ }^{142} \mathrm{Nd}$ composition. Nature 537 , 394-398.

Canup, R.M., 2008. Accretion of the Earth. Phil. Trans. R. Soc. A 366, 4061-4075.

Canup, R.M., 2012. Forming a Moon with an Earth-like composition via a giant impact. Science 338, 1052-1055.

Carlson, R.W., Boyet, M., Horan, M., 2007. Chondrite barium, neodymium, and samarium isotopic heterogeneity and early Earth differentiation. Science 316, 1175-1178.

Carlson, R.W., et al., 2014. How did early Earth become our modern world? Annu. Rev. Earth Planet. Sci. 42, 151-178.

Caro, G., Bourdon, B., Birck, J.L., Moorbath, S., 2006. High precision ${ }^{142} \mathrm{Nd} /{ }^{144} \mathrm{Nd}$ measurements in terrestrial rocks: constraints on the early differentiation of the Earth's mantle. Geochim. Cosmochim. Acta 70, 164-191.

Cartier, C., Hammouda, T., Boyet, M., Bouhifd, M.A., Devidal, J.L., 2014. Redox control on $\mathrm{Nb} / \mathrm{Ta}$ fractionation during planetary accretion. Nat. Geosci. 7, 573-576.

Cartier, C., Hammouda, T., Boyet, M., Mathon, O., Testemale, D., Moine, B.N., 2015. Evidence for $\mathrm{Nb}^{2+}$ and $\mathrm{Ta}^{3+}$ in silicate melts under highly reducing conditions: A XANES study. Am. Mineral. 100, 2152-2158.

Chabot, N.L., Draper, D.S., Agee, C.B., 2005. Conditions of core formation in the Earth: Constraints from nickel and cobalt partitioning. Geochim. Cosmochim. Acta 69, 2141-2151.

Chambers, J.E., 2004. Planetary accretion in the inner solar system. Earth Planet. Sci. Lett. 223, 241-252.

Chamorro-Perez, E., Gillet, P., Jambon, A., 1996. Argon solubility in silicate melts at very high pressures. Experimental set-up and preliminary results for silica and anorthite melts. Earth Planet. Sci. Lett. 145, 97-107.

Clesi, V., Bouhifd, M.A., Bolfan-Casanova, N., Manthilake, G., Fabbrizio, A., Andrault, D., 2016. Effect of $\mathrm{H}_{2} \mathrm{O}$ on metal-silicate partitioning of $\mathrm{Ni}, \mathrm{Co}, \mathrm{V}, \mathrm{Cr}$, Mn and Fe: implications for the oxidation state of the Earth and Mars. Geochim. Cosmochim. Acta 192, 97-121.

Coltice, N., Moreira, M., Herlund, J., Labrosse, S., 2011. Crystallization of a basal magma ocean recorded by helium and neon. Earth Planet. Sci. Lett. 308, 193-199.

Connelly, J.N., Bizzarro, M., Krot, A.N., Nordlund, A., Wielandt, D., Ivanova, M.A., 2012. The absolute chronology and thermal processing of solids in the Solar protoplanetary disk. Science 338, 651-655.

Dahl, T.W., Stevenson, D.J., 2010. Turbulent mixing of metal and silicate during planet accretion and interpretation of the Hf-W chronometer. Earth Planet. Sci. Lett. 295, $177-186$.

Dasgupta, R., Chi, H., Shimizu, N., Buono, A.S., Walker, D., 2013. Carbon solution and partitioning between metallic and silicate melts in a shallow magma ocean: implications for the origin and distribution of terrestrial carbon. Geochim. Cosmochim. Acta $102,191-212$.

Dauphas, N., Chen, J.H., Zhang, J., Papanastassiou, D.A., Davis, A.M., Travaglio, C., 2014. Calcium-48 isotopic anomalies in bulk chondrites and achondrites: Evidence for a uniform isotopic reservoir in the inner protoplanetary disk. Earth Planet. Sci. Lett. 407, 96-108.

Deguen, R., Olson, P., Cardin, P., 2011. Experiments on turbulent metal-silicate mixing in a magma ocean. Earth Planet. Sci. Lett. 310, 303-313.

Deguen, R., Landeau, M., Olson, P., 2014. Turbulent metal-silicate mixing, fragmentation, and equilibration in magma oceans. Earth Planet. Sci. Lett. 391, 274-287.
Doremus, R.H., 1966. Physical solubility of gases in fused silica. J. Am. Ceram. Soc. 49, 461-462.

Elkins-Tanton, L.T., 2012. Magma oceans in the inner solar system. Annu. Rev. Earth Planet. Sci. 40, 113-139.

Fiquet, G., Auzende, L., Siebert, J., Corgne, A., Bureau, H., Ozawa, H., Garbarino, G., 2010. Melting of peridotite to $140 \mathrm{GPa}$. Science $329,1516-1518$.

Fischer, R.A., Ciela, F.J., 2014. Dynamics of the terrestrial planets from a large number of $N$ body simulations. Earth Planet. Sci. Lett. 392, 28-38.

Fischer, R.A., Nakajima, Y., Campbell, A.J., Frost, D.J., Harries, D., Langenhorst, F., Miyajima, N., Pollok, K., Rubie, D.C., 2015. High pressure metal-silicate partitioning of Ni, Co, V, $\mathrm{Cr}, \mathrm{Si}$, and O. Geochim. Cosmochim. Acta 167, 177-194.

Frost, D.J., Langenhorst, F., 2002. The effect of $\mathrm{Al}_{2} \mathrm{O}_{3}$ on Fe-Mg partitioning between magnesiowüstite and magnesium silicate perovskite. Earth Planet. Sci. Lett. 199, 227-241.

Frost, D.J., Liebske, C., Langenhorst, F., McCammon, C.A., Tronnes, R.G., Rubie, D.C., 2004 Experimental evidence for the existence of iron-rich metal in the Earth's lower mantle. Nature 428, 409-412.

Gaillard, F., Scaillet, B., 2014. A theoretical framework for volcanic degassing chemistry in a comparative planetology perspective and implications for planetary atmospheres. Earth Planet. Sci. Lett. 403, 307-316.

Gaillard, F., Scaillet, B., Pichacant, M., Iacono-Marziano, G., 2015. The redox geodynamics linking basalts and their mantle sources through space and time. Chem. Geol. 418, 217-233.

Gannoun, A., Boyet, M., Rizo, H., El Goresy, A., 2011. ${ }^{146} \mathrm{Sm}-{ }^{142} \mathrm{Nd}$ systematics measured in enstatite chondrites reveals a heterogeneous distribution of ${ }^{142} \mathrm{Nd}$ in the solar nebula. PNAS 108, 7693-7697.

Gessmann, C.K., Rubie, D.C., 2000. The origin of the depletions of V, $\mathrm{Cr}$ and $\mathrm{Mn}$ in the mantles of the Earth and Moon. Earth Planet. Sci. Lett. 184, 95-107.

Goldschmidt, V.M., 1937. The principles of distribution of chemical elements in minerals and rocks. The Seventh Hugo Müller Lecture, Delivered before the Chemical Society on March 17th, 1937.

Greenwood, R.C., Franchi, I.A., Jambon, A., Buchanan, P.C., 2005. Widespread magma oceans on asteroidal bodies in the early solar system. Nature 435, 916-918.

Grossman, L., 1972. Condensation in the primitive solar nebula. Geochim. Cosmochim. Acta 36, 597-619.

Grossman, L., Beckett, J.R., Fedkin, A.V., Simon, S.B., Ciesla, F.J., 2008. Redox conditions in the solar nebula: observational, experimental, and theoretical constraints. Rev. Mineral. Geochem. 68, 93-140.

Guillot, B., Sator, N., 2012. Noble gases in high-pressure silicate liquids: a computer simulation study. Geochim. Cosmochim. Acta 80, 51-69.

Halliday, A.N., 2013. The origins of volatiles on the terrestrial planets. Geochim. Cosmochim. Acta 105, 146-171.

Halliday, A.N., Wood, B.J., 2009. How did Earth accrete? Science 325, 44-45.

Harper, C.L., Jacobsen, S.B., 1996. Noble gases and Earth's accretion. Science 273 1814-1818.

Hartmann, W.K., Davis, D.R., 1975. Satellite-sized planetesimals and lunar origin. Icarus 24, 504-514.

Heber, V.S., Brooker, R.A., Kelley, S.P., Wood, B.J., 2007. Crystal-melt partitioning of noble gases (helium, neon, argon, krypton, and xenon) for olivine and clinopyroxene. Geochim. Cosmochim. Acta 71, 1041-1061.

Herzberg, C., et al., 2013. Nickel and helium evidence for melt above the core-mantle boundary. Nature 493, 393-397.

Hirschmann, M.M., 2016. Constraints on the early delivery and fractionation of Earth's major volatiles from $\mathrm{C} / \mathrm{H}, \mathrm{C} / \mathrm{N}$, and $\mathrm{C} / \mathrm{S}$ ratios. Am. Mineral. 101, 540-553.

Hirschmann, M.M., Dasgupta, R., 2009. The H/C ratios of Earth's near-surface and deep reservoirs, and consequences for deep Earth volatile cycles. Chem. Geol. 262, 4-16.

Hirschmann, M.M., Withers, A.C., Ardia, P., Foley, N.T., 2012. Solubility of molecular hydrogen in silicate melts and consequences for volatile evolution of terrestrial planets. Earth Planet. Sci. Lett. 345-348, 38-48.

Hofmann, A.W., 1988. Chemical differentiation on the Earth: the relationship between mantle, continental crust, and oceanic crust. Earth Planet. Sci. Lett. 90, 297-314.

Honda, M., McDougall, I., Patterson, D.B., Doulgeris, A., Clague, D.A., 1991. Possible solar noble-gas component in Hawaiian basalts. Nature 349, 149-151.

Javoy, M., 1995. The integral enstatite chondrite model of the Earth. Geophys. Res. Lett. 22 2219-2222.

Javoy, M., et al., 2010. The chemical composition of the Earth: enstatite chondrite models Earth Planet. Sci. Lett. 293, 259-268.

Jephcoat, A.P., Bouhifd, M.A., Porcelli, D., 2008. Partitioning experiments in the laser-heated diamond anvil cell: volatile content in the Earth's core. Phil. Trans. R. Soc. A 366 4295-4314.

Kadik, A.A., Koltashev, V.V., Kryukova, E.B., Plotnichenko, V.G., Tsekhonya, T.I., Kononkova N.N., 2015. Solubility of nitrogen, carbon, and hydrogen in $\mathrm{FeO}-\mathrm{Na}_{2} \mathrm{O}-\mathrm{Al}_{2} \mathrm{O}_{3}-\mathrm{SiO}_{2}$ mel and liquid iron alloy: influence of oxygen fugacity. Geochem. Int. 53, 849-868.

Kargel, J.S., Lewis, J.S., 1993. The composition and early evolution of Earth. Icarus 105, $1-25$.

Ke, Y., Solomatov, V.S., 2009. Coupled core-mantle thermal evolution of early Mars. J. Geophys. Res. Planets 114 (13), 1-12.

Kleine, T., Touboul, M., Bourdon, B., Nimmo, F., Mezger, K., Palme, H., Jacobsen, S.B. Yin, Q.-Z., Halliday, A.N., 2009. Hf-W chronology of the accretion and early evolution of asteroids and terrestrial planets. Geochim. Cosmochim. Acta 73, 5150-5188.

Kruijer, T.S., Sprung, P., Kleine, T., Leya, I., Burkhardt, C., Wieler, R., 2012. Hf-W chronometry of core formation in planetesimals inferred from weakly irradiated iron meteorites. Geochim. Cosmochim. Acta 99, 287-304.

Kruijer, T.S., Fischer-Gödde, M., Kleine, T., Burkhardt, C., Wieler, R., 2014. Nucleosynthetic $\mathrm{W}$ isotope anomalies and the Hf-W chronometry of Ca-Al-rich inclusions. Earth Planet. Sci. Lett. 403, 317-327. 
Labrosse, S., Hernlund, J.W., Coltice, N., 2007. A crystallizing dense magma ocean at the base of the Earth's mantle. Nature 450, 866-869.

Larimer, J.W., Buseck, P.R., 1974. Equilibration temperatures in enstatite chondrites. Geochim. Cosmochim. Acta 38, 471-477.

Lauterbach, S., McCammon, C.A., van Aken, P., Langenhorst, F., Seifert, F., 2000. Mössbauer and ELNES spectroscopy of $(\mathrm{Mg}, \mathrm{Fe})(\mathrm{Si}, \mathrm{Al}) \mathrm{O}_{3}$ perovskite: a highly oxidized component of the lower mantle. Contrib. Mineral. Petrol. 138, 17-26.

Lay, T., Garnero, E.J., Williams, Q., 2004. Partial melting in a thermo-chemical boundary layer at the base of the mantle. Phys. Earth Planet. Inter. 146, 441-467.

Li, J., Agee, C.B., 1996. Geochemistry of mantle-core differentiation at high pressure. Nature 381, 686-689.

Li, J., Agee, C.B., 2001. The effect of pressure, temperature, oxygen fugacity and composition on partitioning of nickel and cobalt between liquid $\mathrm{Fe}-\mathrm{Ni}-\mathrm{S}$ and liquid silicate: implications for the Earth's core formation. Geochim. Cosmochim. Acta 65, 1821-1832.

Li, Y., Dasgupta, R., Tsuno, K., Monteleone, B., Shimizu, N., 2016. Carbon and sulfur budget of the silicate Earth explained by accretion of differentiated planetary embryos. Nat Geosci. 7, 781-785.

Lupton, J.E., Craig, H., 1975. Excess ${ }^{3} \mathrm{He}$ in oceanic basalts; evidence for terrestrial primordial helium. Earth Planet. Sci. Lett. 26, 133-139.

Macpherson, C.G., Hilton, D.R., Sinton, J.M., Poreda, R.J., Craig, H., 1998. High ${ }^{3} \mathrm{He} /{ }^{4} \mathrm{He}$ ratios in the Manus backarc basin: Implications for mantle mixing and the origin of plumes in the western Pacific Ocean. Geology 26, 1007-1010.

Malavergne, V., Tarrida, M., Combes, R., Bureau, H., Jones, J., Schwandt, C., 2007. New highpressure and high-temperature metal/silicate partitioning of $\mathrm{U}$ and $\mathrm{Pb}$ : implications for the cores of the Earth and Mars. Geochim. Cosmochim. Acta 71, 2637-2655.

Mann, U., Frost, D.J., Rubie, D.C., 2009. Evidence for high pressure core-mantle differentiation from the metal-silicate partitioning of lithophile and weakly-siderophile elements. Geochim. Cosmochim. Acta 73, 7360-7386.

Marty, B., 2012. The origins and concentrations of water, carbon, nitrogen and noble gases on Earth. Earth Planet. Sci. Lett. 313-314, 56-66.

Marty, B., Alexander, C.M.O.'.D., Raymond, S.N., 2013. Primordial origins of Earth's carbon. Rev. Mineral. Geochem. 75, 149-181.

McCammon, C.A., Lauterbach, S., Seifert, F., Langenhorst, F., van Aken, P.A., 2004. Iron oxidation state in lower mantle mineral assemblages. I. Empirical relations derived from high-pressure experiments. Earth Planet. Sci. Lett. 222, 435-449.

McDonough, W.F., Sun, S.-S., 1995. The composition of the Earth. Chem. Geol. 120 223-253.

Mizuno, H., Nakazawa, K., Hayashi, C., 1980. Dissolution of the primordial rare gases into the molten Earth's material. Earth Planet. Sci. Lett. 50, 202-210.

Monteux, J., Ricard, Y., Coltice, N., Dubuffet, F., Ulvrova, M., 2009. A model of metal- silicate separation on growing planets. Earth Planet. Sci. Lett. 287, 353-362.

Monteux, J., Andrault, D., Samuel, H., 2016. On the cooling of a deep terrestrial magma ocean, Earth and planet. Sci. Lett. 448, 140-149.

Morbidelli, A., Lunine, J.I., O'Brien, D.P., Raymond, S.N., Walsh, K.J., 2012. Building terrestrial planets. Annu. Rev. Earth Planet. Sci. 40, 251-275.

Moreira, M., 2013. Noble gas constraints on the origin and evolution of Earth's volatiles. Geochem. Perspect. 2, 229-403.

Moreira, M., Charnoz, S., 2016. The origin of the neon isotopes in chondrites and on Earth. Earth Planet. Sci. Lett. 433, 249-256.

Mosenfelder, J.L., Asimow, P.D., Ahrens, T.J., 2007. Thermodynamic properties of $\mathrm{Mg}_{2} \mathrm{SiO}_{4}$ liquid at ultra-high pressures from shock measurements to $200 \mathrm{GPa}$ on forsterite and wadsleyite. J. Geophys. Res. Solid Earth 112:B06208. http://dx.doi.org/10.1029/ 2006JB004364.

Mosenfelder, J.L., Asimow, P.D., Frost, D.J., Rubie, D.C., Ahrens, T.J., 2009. The MgSiO3 system at high pressure: thermodynamic properties of perovskite, postper- ovskite, and melt from global inversion of shock and static compression data. J. Geophys. Res. Solid Earth 114:B01203. http://dx.doi.org/10.1029/2008JB005900.

Mukhopadhayay, S., 2012. Early differentiation and volatile accretion recorded in deepmantle neon and xenon. Nature 486, 101-104.

Münker, C., Pfänder, J.A., Weyer, S., Büchl, A., Kleine, T., Mezger, K., 2003. Evolution of planetary cores and the Earth-Moon system from Nb/Ta systematics. Science 301, $84-87$

Nagahara, H., Ozawa, K., 1996. Evaporation of forsterite in H-2 gas. Geochim. Cosmochim. Acta 60, 1445-1459.

Nakajima, M., Stevenson, D.J., 2015. Melting and mixing states of the Earth's mantle after the Moon-forming impact. Earth Planet. Sci. Lett. 427, 286-295.

Nakajima, Y., Frost, D.J., Rubie, D.C., 2012. Ferrous iron partitioning between magnesium silicate perovskite and ferropericlase and the composition of perovskite in the Earth's lower mantle. J. Geophys. Res. 117, 1-12.

Nebel, O., van Westrenen, W., Vroon, P.Z., Wille, M., Raith, M.M., 2010. Deep mantle storage of the Earth's missing niobium in late-stage residual melts from a magma ocean. Geochim. Cosmochim. Acta 74, 4392-4404.

Nevins, D., Spera, F.J., 1998. Molecular dynamics simulations of molten $\mathrm{CaAl}_{2} \mathrm{Si}_{2} \mathrm{O}_{8}$ : dependence of structure and properties on pressure. Am. Mineral. 83, 1220-1230.

Newsom, H.E., 1990. Accretion and core formation in the Earth: evidence from siderophile elements. In: Newson, H.E., Jones, J.H. (Eds.), Origin of the Earth. Oxford University Press, New York, pp. 273-288.

Niwa, K., Miyakawa, C. Yagi, T., Matsuda, J. 2013. Argon solubility in $\mathrm{SiO}_{2}$ melt under high pressures: a new experimental result using laser-heated diamond anvil cell. Earth Planet. Sci. Lett. 363, 1-8.

Nomura, R., Ozawa, H., Tateno, S., Hirose, K., Hernlund, J.W., Muto, S., Ishii, H., Hiraoka, N. 2011. Spin crossover and iron-rich silicate melt in the Earth's deep mantle. Nature 473, 199-202.

Nomura, R., Hirose, K., Uesugi, K., Ohishi, Y., Tsuchiyama, A., Miyake, A., Ueno, Y., 2014 Low core-mantle boundary temperature inferred from the solidus of pyrolite. Science $343,522-525$.
O'Brien, D.P., Morbidelli, A., Levison, H.F., 2006. Terrestrial planet formation with strong dynamical friction. Icarus 184, 39-58.

Ohtani, E., Yurimoto, H., 1996. Element partitioning between metallic liquid, magnesiowustite, and silicate liquid at $20 \mathrm{GPa}$ and $2500{ }^{\circ} \mathrm{C}$ : a secondary ion mass spectrometric study. Geophys. Res. Lett. 23, 1993-1996.

O'Neill, H.S.C., Palme, H., 1998. Composition of the silicate Earth: implications for accretion and core formation. In: Jackson, I. (Ed.), The Earth's Mantle, Composition, Structure, and Evolution. Cambridge University Press, pp. 3-126.

O'Neill, H.S.C., Canil, D., Rubie, D.C., 1998. Oxide-metal equilibria to $2500{ }^{\circ} \mathrm{C}$ and $25 \mathrm{GPa}$ : Implications for core formation and the light component in the Earth's core. J. Geophys. Res. 103, 12239-12260.

Pepin, R.O., Porcelli, D., 2006. Xenon isotope systematics, giant impacts, and mantle degassing on the early Earth. Earth Planet. Sci. Lett. 250, 470-485.

Porcelli, D., Ballentine, C.J., 2002. Models for the distribution of terrestrial noble gases and evolution of the atmosphere. Rev. Mineral. Geochem. 46, 411-480.

Porcelli, D., Halliday, A.N., 2001. The core as a possible source of mantle helium. Earth Planet. Sci. Lett. 192, 45-56.

Porcelli, D., Woolum, D., Cassen, P., 2001. Deep Earth rare gases: initial inventories, capture from the solar nebula, and losses during Moon formation. Earth Planet. Sci. Lett. 193, 237-251.

Pradhan, G.K., Fiquet, G., Siebert, J., Auzende, A.-L., Morard, G., Antonangeli, D., Garbarino, G., 2015. Melting of MORB at core-mantle boundary. Earth Planet. Sci. Lett. 431, 247-255.

Press, W.H., Teukolsky, S.A., Vetterling, W.T., Flannery, B.P., 1993. Numerical Recipes in FORTRAN the Art of Scientific Computing. second ed. Cambridge University Press, New York, NY, USA

Raymond, S.N., Quinn, T., Lunine, J.I., 2006. High-resolution simulations of the final assembly of Earth-like planets I. Terrestrial accretion and dynamics. Icarus 183, 265-282.

Revenaugh, J., Meyer, R., 1997. Seismic evidence of partial melt within a possibly ubiquitous low-velocity layer at the base of the mantle. Science 277, 670-673.

Righter, K., 2011. Prediction of metal-silicate partition coefficients for siderophile elements: an update and assessment of PT conditions for metal-silicate equilibrium during accretion of the earth. Earth Planet. Sci. Lett. 304, 158-167.

Rizo, H., Boyet, M., Blichert-Toft, J., Rosing, M., 2011. Combined Nd and Hf isotope evidence for deep-seated source of Isua lavas. Earth Planet. Sci. Lett. 312, 267-279.

Rizo, H., Boyet, M., Blichert-Toft, J., Rosing, M.T., 2013. Early mantle dynamics inferred from Nd-142 variations in Archean rocks from southwest Greenland. Earth Planet. Sci. Lett. 377, 324-335.

Rizo, H., et al., 2016. Preservation of Earth-forming events in the tungsten isotopic composition of modern flood basalts. Science 352, 809-812.

Roskosz, M., Bouhifd, M.A., Jephcoat, A.P., Marty, B., Mysen, B.O., 2013. Nitrogen solubility in molten metal and silicate at high pressure and temperature. Geochim. Cosmochim. Acta $121,15-28$

Rost, S., Garnero, E.J., Williams, Q., 2005. Seismological constraints on a possible plume root at the core-mantle boundary. Nature 435, 666-669.

Rubie, D.C., Melosh, H.J., Reid, J.E., Liebske, C., Righter, K., 2003. Mechanisms of metal- silicate equilibration in the terrestrial magma ocean. Earth Planet. Sci. Lett. 205, 239-255.

Rubie, D.C., Gessmann, C.K., Frost, D.J., 2004. Partitioning of oxygen during core formation on the Earth and Mars. Nature 429, 58-61.

Rubie, D.C., Frost, D.J., Mann, U., Asahara, Y., Nimmo, F., Tsuno, K., Kegler, P., Holzheid, A., Palme, H., 2011. Heterogeneous accretion, composition and core-mantle differentiation of the Earth. Earth Planet. Sci. Lett. 301, 31-42.

Rubie, D.C., et al., 2015a. Accretion and differentiation of the terrestrial planets with implications for the compositions of early-formed solar system bodies and accretion of water. Icarus 248, 89-108.

Rubie, D.C., Nimmo, F., Melosh, H.J., 2015b. Formation of the Earth's core. treatise on geophysics, second edition. In: Stevenson, D. (Ed.), Evolution of the Earth 9. Elsevier, Amsterdam, pp. 43-79.

Rudnick, R., Barth, M., Horn, I., McDonough, W., 2000. Rutile-bearing refractory eclogites: missing link between continents and depleted mantle. Science 287, 278-281.

Samuel, H., 2012. A re-evaluation of metal diapir breakup and equilibration in terrestrial magma oceans. Earth Planet. Sci. Lett. 313, 105-114.

Samuel, H., Tackley, P.J., Evonuk, M., 2010. Heat partitioning in terrestrial planets during core formation by negative diapirism. Earth Planet. Sci. Lett. 290, 13-19.

Saikia, A., Boffa Ballaran, T., Frost, D.J., 2009. The effect of Fe and Al substitution on the compressibility of MgSiO3-perovskite determined through single-crystal X ray diffraction. Phys. Earth Planet. Inter. 173, 153-161.

Sanloup, C., et al., 2013. Structural change in molten basalt at deep mantle conditions. Nature 503, 104-107.

Schiano, P., Provost, A., Clocchiatti, R., Faure, F., 2006. Transcrystalline melt migration and Earth's mantle. Science 314, 970-974.

Shackelford, J.F., Studt, P.L., Fulrath, R.M., 1972. Solubility of gases in glass II. He, Ne, and $\mathrm{H}_{2}$ in fused silica. J. Appl. Phys. 43, 1619-1626.

Shannon, R.D., 1976. Revised effective ionic radii and systematic studies of interatomic distances in halides and chalcogenides. Acta Crystallogr. Sect. A: Cryst. Phys. Diffr. Theor. Gen. Crystallogr. 32, 751-767

Shelby, J.E., 1976. Pressure dependence of helium and neon solubility in vitreous silica. J. Appl. Phys. 47, 135-139.

Siebert, J., Corgne, A., Ryerson, F.J., 2011. Systematics of metal-silicate partitioning for many siderophile elements applied to Earth's core formation. Geochim. Cosmochim. Acta $75,1451-1489$.

Siebert, J., Badro, J., Antonangeli, D., Ryerson, F.J., 2012. Metal-silicate partitioning of Ni and Co in a deep magma ocean. Earth Planet. Sci. Lett. 321-322, 189-197.

Siebert, J., Badro, J., Antonangeli, D., Ryerson, F.J., 2013. Terrestrial accretion under oxidizing conditions. Science 339, 1194-1197. 
Sleep, N.H., Zahnle, K.J., Neuhoff, P.S., 2001. Initiation of clement surface conditions on the earliest Earth. Proc. Natl. Acad. Sci. 98, 3666-3672.

Solomatov, V.S., 2007. Magma oceans and primordial mantle differentiation. In: Schubert, G. (Ed.)first ed. Treatise on Geophysics v. 9. Elsevier, pp. 91-119.

Stevenson, D.J., 1990. In: Newsom, H.E., Jones, J.H. (Eds.), Fluid dynamics of core formation, in the Origin of the Earth. Oxford University Press.

Studt, P.L., Shackelford, J.F., Fulrath, R.M., 1970. Solubility of gases in glass: a monoatomic model. J. Appl. Phys. 44, 2777-2780.

Tackley, P.J., 2012. Dynamics and evolution of the deep mantle resulting from thermal, chemical, phase and melting effects. Earth Sci. Rev. 110, 1-25.

Tateno, S., Hirose, K., Ohishi, Y., 2014. Melting experiments on peridotite to lowermost mantle conditions. J. Geophys. Res. Solid Earth 119, 4684-4694.

Terasaki, H., Frost, D.J., Rubie, D.C., Langenhorst, F., 2007. Interconnectivity of Fe-O-S liquid in polycrystalline silicate perovskite at lower mantle conditions. Phys. Earth Planet. Inter. 161, 170-176.

Thibault, Y., Walter, M.J., 1995. The influence of pressure and temperature on the metalsilicate partition coefficients of nickel and cobalt in a model C1 chondrite and implications for metal segregation in a deep magma ocean. Geochim. Cosmochim. Acta 59, 991-1002.

Thomas, C.W., Asimow, P.D., 2013. Direct shock compression experiments on premolten forsterite and progress toward a consistent high-pressure equation of state for $\mathrm{CaO}$ $\mathrm{MgO}-\mathrm{Al}_{2} \mathrm{O}_{3}-\mathrm{SiO}_{2}-\mathrm{FeO}$ liquids. J. Geophys. Res. Solid Earth 118, 5738-5752.

Thomas, C.W., Liu, Q., Agee, C.B., Asimow, P.D., Lange, R.A., 2012. Multi-technique equation of state for Fe2SiO4 melt and the density of Fe-bearing silicate melts from 0 to $161 \mathrm{GPa}$. J. Geophys. Res. Solid Earth 117:B10206. http://dx.doi.org/10.1029/2012JB009403.

Tonks, W.B., Melosh, H.J., 1993. Magma ocean formation due to giant impacts. J. Geophys. Res. 98, 5319-5333.

Touboul, M., Puchtel, I.S., Walker, R.J., 2012. ${ }^{182} \mathrm{~W}$ evidence for long-term preservation of early mantle differentiation products. Science 335, 1065-1069.

Touboul, M., Sprung, P., Aciego, S.M., Bourdon, B., Kleine, T., 2015. Hf-W chronology of the eucrite parent body. Geochim. Cosmochim. Acta 156, 106-121.

Trieloff, M., Kunz, J., 2005. Isotope systematics of noble gases in the Earth's mantle: possible sources of primordial isotopes and implications for mantle structure. Phys. Earth Planet. Inter. 148, 13-38.

Tsuno, K., Frost, D.J., Rubie, D.C., 2013. Simultaneous partitioning of silicon and oxygen into the Earth's core during early Earth differentiation. Geophys. Res. Lett. 40, 66-71.

Tucker, J.M., Mukhopadhyay, S., 2014. Evidence for multiple magma ocean outgassing and atmospheric loss episodes from mantle noble geases. Earth Planet. Sci. Lett. 393, 254-265.

Valley, J.W., et al., 2014. Hadean age for post-magma-ocean zircon confirmed by atomprobe tomography. Nat. Geosci. 7, 219-223.
Vidale, J.E., Hedlin, M.A.H., 1998. Evidence for partial melt at the core-mantle boundary north of Tonga from the strong scattering of seismic waves. Nature 391, 682-685.

Wacheul, J.B., Le Bars, M., Monteux, J., Aurnou, J.M., 2014. Laboratory experiments on the breakup of liquid metal diapirs. Earth Planet. Sci. Lett. 403, 236-245.

Wade, J., Wood, B.J., 2001. The Earth's "missing" niobium may be in the core. Nature 409 75-78.

Wade, J., Wood, B.J., 2005. Core formation and the oxidation state of the Earth. Earth Planet. Sci. Lett. 236, 78-95.

Warren, P.H., 2011. Stable-isotopic anomalies and the accretionary assemblage of the Earth and Mars: a subordinate role for carbonaceous chondrites. Earth Planet. Sci. Lett. 311, 93-100.

Wetherill, G.W., 1985. Occurrence of giant impacts during the growth of terrestrial planets. Science 228, 877-879.

Wheeler, K.T., Walker, D., Fei, Y., Minarik, W.G., McDonough, W.F., 2006. Experimental partitioning of uranium between liquid iron sulfide and liquid silicate: implications for radioactivity in the Earth's core. Geochim. Cosmochim. Acta 70, 1537-1547.

White, B.S., Brearly, M., Montana, A., 1989. Solubility of argon in silicate liquids at high pressures. Am. Mineral. 74, 513-529.

Wicks, J.K., Jackson, J.M., Sturhahn, W., 2010. Very low sound velocities in iron-rich (Mg,Fe)O: Implications for the core-mantle boundary region. Geophys. Res. Lett. 37, L15304. http://dx.doi.org/10.1029/2010GL043689.

Wilde, S.A., Valley, J.W., Peck, W.H., Graham, C.M., 2001. Evidence from detritical zircons for the existence of continental crust and oceans on the Earth 4.4 Gyr ago. Nature 409 175-178.

Williams, Q., Garnero, E.J., 1996. Seismic evidence for partial melt at the base of Earth's mantle. Science 273, 1528-1530.

Wood, B.J., Walter, M.J., Wade, J., 2006. Accretion of the Earth and segregation of its core Nature 441, 825-833.

Wood, B.J., Li, J., Shahar, A., 2013. Carbon in the core: influence on the properties of core and mantle. Rev. Mineral. Geochem. 75, 231-250.

Yokochi, R., Marty, B., 2005. Geochemical constraints on mantle dynamics in the Hadean. Earth Planet. Sci. Lett. 238, 17-30.

Yoshino, T., Walter, M., Katsura, T., 2003. Core formation in planetesimals triggered by permeable flow. Nature 422, 154-157.

Zahnle, K.J., Kastings, J.F., Pollack, J.B., 1988. Evolution of a steam atmosphere during Earth's accretion. Icarus 74, 62-97.

Zhang, Y., Yin, Q.Z., 2012. Carbon and other light element contents in the Earth's core based on first-principles molecular dynamics. Proc. Natl. Acad. Sci. U. S. A. 109 16579-16583. 